OPEN ACCESS

Edited by:

Andrei Surguchov, Kansas University of Medical Center Research Institute, United States

Reviewed by:

Subhrangshu Guhathakurta, University of Central Florida, United States

José A. G. Agúndez, Universidad de Extremadura, Spain

${ }^{*}$ Correspondence: Nor Azian Abdul Murad nor_azian@ppukm.ukm.edu.my

Received: 22 June 2017 Accepted: 13 October 2017 Published: 31 October 2017

Citation:

Arshad AR, Sulaiman SA, Saperi AA, Jamal $R$, Mohamed Ibrahim N and Abdul Murad NA (2017) MicroRNAs and Target Genes As Biomarkers for the Diagnosis of Early Onset of Parkinson Disease.

Front. Mol. Neurosci. 10:352. doi: $10.3389 /$ fnmol.2017.00352

\section{MicroRNAs and Target Genes As Biomarkers for the Diagnosis of Early Onset of Parkinson Disease}

\author{
Ahmad R. Arshad ${ }^{1}$, Siti A. Sulaiman ${ }^{1}$, Amalia A. Saperi ${ }^{1}$, Rahman Jamal ${ }^{1}$, \\ Norlinah Mohamed Ibrahim ${ }^{2}$ and Nor Azian Abdul Murad ${ }^{1 *}$ \\ ${ }^{1}$ UKM Medical Centre, UKM Medical Molecular Biology Institute, Universiti Kebangsaan Malaysia, Bandar Tun Razak, \\ Malaysia, ${ }^{2}$ Department of Medicine, Faculty of Medicine, UKM Medical Centre, Universiti Kebangsaan Malaysia, Bandar Tun \\ Razak, Malaysia
}

Among the neurodegenerative disorders, Parkinson's disease (PD) ranks as the second most common disorder with a higher prevalence in individuals aged over 60 years old. Younger individuals may also be affected with PD which is known as early onset PD (EOPD). Despite similarities between the characteristics of EOPD and late onset PD (LODP), EOPD patients experience much longer disease manifestations and poorer quality of life. Although some individuals are more prone to have EOPD due to certain genetic alterations, the molecular mechanisms that differentiate between EOPD and LOPD remains unclear. Recent findings in PD patients revealed that there were differences in the genetic profiles of PD patients compared to healthy controls, as well as between EOPD and LOPD patients. There were variants identified that correlated with the decline of cognitive and motor symptoms as well as non-motor symptoms in PD. There were also specific microRNAs that correlated with PD progression, and since microRNAs have been shown to be involved in the maintenance of neuronal development, mitochondrial dysfunction and oxidative stress, there is a strong possibility that these microRNAs can be potentially used to differentiate between subsets of PD patients. PD is mainly diagnosed at the late stage, when almost majority of the dopaminergic neurons are lost. Therefore, identification of molecular biomarkers for early detection of PD is important. Given that miRNAs are crucial in controlling the gene expression, these regulatory microRNAs and their target genes could be used as biomarkers for early diagnosis of PD. In this article, we discussed the genes involved and their regulatory miRNAs, regarding their roles in PD progression, based on the findings of significantly altered microRNAs in EOPD studies. We also discussed the potential of these miRNAs as molecular biomarkers for early diagnosis.

Keywords: Parkinson's disease (PD), microRNA (miRNA), PD related genes, biomarkers, early onset

\section{INTRODUCTION}

Parkinson's disease (PD) is the second most common neurodegenerative disorder with an approximate incidence of 1:800-1,000 in subjects aged over 60 years old (Bekris et al., 2010; Lin and Farrer, 2014). PD is a progressive disorder that affects movement that is often diagnosed based on the presence of motor signs such as tremor, bradykinesia, muscle rigidity, and postural 
instability though in some PD patients, non-motor symptoms of anxiety, fatigue, depression, sleep disturbance, gastrointestinal, and sexual dysfunctions are also observed (Schneider and Obeso, 2015). As PD is an age-related disorder, it is more common in the elderly; however younger individuals may also be affected (Gasser et al., 2011) and these patients are usually known as early onset PD (EOPD) patients. The typical PD, or also known as late onset PD (LOPD), is defined for individuals more than 50 years old who exhibit PD signs and symptoms (Schrag and Schott, 2006). Some of EOPD patients show slower disease progression and worse disease outcomes in comparison to LOPD patients (Schrag et al., 1998; Inzelberg et al., 2004; Ferguson et al., 2015), implying that there could be biological differences that dictates the disease outcomes and also the age of onset of PD. There are some evidence that EOPD may be associated with some genetic alterations in the PD progression (Oki et al., 2016), yet the molecular mechanisms to differentiate the EOPD and LOPD progression remains unclear and requires further understanding.

Parkinson's disease (PD) is a multi-factorial disease involving interactions between environment and genetic factors (Farrer, 2006; Sellbach et al., 2006). Initially, PD is thought to be a sporadic disease due to environmental factors such as exposure to toxins namely, paraquat, 1-methyl-4-phenyl-1,2,3,6tetrahyropyridine (MPTP) or pesticides (Langston et al., 1983; Ascherio and Schwarzschild, 2016). However, in the past few decades, genetic inheritance has been also identified to be one of the causative factors that could contribute to PD progression (Gasser et al., 2011; Lin and Farrer, 2014). About 90\% of PD cases are sporadic whereas $>10 \%$ of PD patients have a family history with the contribution of one or several genetic alterations (Klein and Westenberger, 2012; Ascherio and Schwarzschild, 2016). These genetic alterations in PD can be categorized into autosomal dominant (AD) and autosomal recessive (AR) of $\mathrm{PD}$ (Bekris et al., 2010; Klein and Westenberger, 2012). The AD form of PD is associated with alterations of the $\alpha$-synuclein (SNCA) and leucine rich repeat kinase 2 (LRRK2) genes (Bekris et al., 2010; Klein and Westenberger, 2012) whereas the Parkin RBR E3 ubiquitin protein ligase $(P R K N)$, Parkinsonism associated deglycase (PARK7), PTEN induced putative kinase 1 (PINK1) and ATPase 13A2 (ATP13A2) genes are linked to the AR form of PD (Nuytemans et al., 2010; Heman-Ackah et al., 2013). Current effective treatments for both motor and non-motor symptoms in PD are available, yet the heterogeneous nature of this disease causes diverse clinical manifestations across the PD patients (Oertel and Schulz, 2016) reducing the effectiveness of those treatments. Moreover, the underlying mechanisms of PD are still poorly understood and the lack of effective approach to differentiate and identify the EOPD and LOPD patients also contribute to the complexity of PD management. Therefore, finding the early diagnostic approaches for EOPD and LOPD are essential for better disease management.

Biological markers, or biomarkers like proteins or other molecular elements which are expressed by cells and tissues can reflect the pathological processes underlying PD progression. The fact that these biomarkers can readily be found in body fluids, such as in blood, urine, or even in cerebrospinal fluid (CSF) (Gwinn et al., 2017) therefore they are the most suitable biomarkers which can accurately diagnose the disease and symptoms, as well as predicting the severity and progression. One such biomarker is microRNAs (miRNAs), in which the recent discovery of miRNAs involvement in PD has garnered interest especially their roles in disease progression (Serafin et al., 2014). miRNAs are single non-coding small RNAs (19-24 nucleotides), which are able to regulate gene expression by mRNA repression or mRNA cleavage (Bartel, 2004). Compared to other organs, there are more miRNAs expressed in the human brain, in which previous studies observed that the function of these brain miRNAs are not only restricted to cell fate determination (Meza-Sosa et al., 2014), but are also involved in neuroplasticity and neurobiological functions (Qiu et al., 2015; Batistela et al., 2017). Dysregulation of these miRNAs leads to mitochondrial dysfunction, altered mitochondrial dynamics, accumulation of fragmented mitochondria, oxidative stress, excitotoxicity, cell death and $\alpha$-synuclein aggregation, thus subsequently causing neurodegeneration (Martin, 2010; Spano et al., 2015). Since a single miRNA can regulate different genes and a single target gene may also be regulated by multiple miRNAs (Qiu et al., 2015), this network regulation of miRNAs and their complementary target mRNAs may provide additional insights on the disease progression and possible new therapeutic approaches. Given these interests, this mini review aimed to discuss the role of $\mathrm{PD}$ related genes and their regulatory microRNAs to differentiate the early-onset (EOPD) and late-onset PD (LOPD). The applications and challenges of using these microRNAs as potential biomarkers are also discussed.

\section{EARLY AND LATE ONSET OF PARKINSON DISEASE}

Within the PD patients, those who are below 50 years old when they first exhibited the PD symptoms are classified as EOPD, which is less common compared to LOPD, or typical PD (Schrag et al., 1998; Schrag and Schott, 2006). The mortality of EOPD is two times greater than typical PD cases (Schrag et al., 1998). EOPD patients experience a longer disease course, with slower disease progression and cognitive decline, yet some motor complications such as dyskinesia and dystonia have been observed to develop earlier than LOPD (Schrag et al., 1998; Inzelberg et al., 2004; Ferguson et al., 2015), consequently causing a significant impairment in the quality of life. In fact, a previous study showed that between EOPD and LOPD patients, the dopaminergic neurons (DA) loss is greater in the EOPD group (Fereshtehnejad et al., 2014), implying that there are differences in the underlying pathophysiology and molecular mechanisms. However, more definitive and confirmatory studies are needed to differentiate between these two subsets of PD patients for better management and personalized treatment.

Parkinson's disease (PD) symptoms are usually present when about $70-80 \%$ of the dopaminergic (DA) neurons are lost (Goldenberg, 1990). The neuropathological hallmark of PD is the deposition of the intracytoplasmic protein inclusions known as Lewy bodies (LB) that are composed of various molecules including $\alpha$-synuclein (protein product of SNCA gene) 
aggregates, which is responsible for the loss of DA neurons in the midbrain of substantia nigra (Spillantini et al., 1997; Wakabayashi et al., 2007; Longhena et al., 2017). Currently, there is no test or examination that can be performed to diagnose PD at an early stage accurately. The standard approach for PD diagnosis is based on the patient's and family history, and on neurological examination to demonstrate the presence of the common signs and symptoms including bradykinesia, rigidity, and tremor (Massano and Bhatia, 2012). Magnetic resonance imaging has also been used as a tool to analyse for brain abnormalities in which multisystem atrophy, progressive supranuclear palsy or cortical degeneration were identified to differentiate between PD and atypical parkinsonism (Ba and Martin, 2015). However, the sensitivity for this MRI diagnosis was only around 60-80\% (Kraft et al., 2002; Feng et al., 2015; Hwang et al., 2015) thus limiting its diagnostic value. Nevertheless, the confirmative diagnosis of PD can only be done through a neuropathological investigation by detecting the loss of DA neurons and the presence of LB and Lewy neurites in the brain (Braak et al., 2003; Massano and Bhatia, 2012).

There is currently no single genetic test to accurately identify those who are susceptible to PD. However, recent findings showed that some genetic markers can be used to diagnose EOPD. Genes such as PRKN, PARK7, PINK1, LRRK2, and Glucosylceramidase beta $(G B A)$ have been consistently shown to be associated with age of onset in PD exclusively (Klein and Westenberger, 2012; Lin and Farrer, 2014). Several genetic mutations in PRKN have been associated with EOPD (Deng et al., 2008; Chen H. et al., 2016) in which the frequency of this gene mutations in the EOPD population is about $7.2-12.5 \%$ (Hardy et al., 2009). In fact, mutations in PRKN gene are the most common cause for EOPD that account for $50 \%$ of those EOPD patients (onset age $<25$ years) and about $3-7 \%$ for EOPD patients (onset age $=30-45$ years) (Lücking et al., 2000; Periquet et al., 2003). Thus, $P R K N$ gene is likely to be the main player of genetic susceptibility in PD progression at a much earlier age. A more rare genetic association was observed for PINK1 gene, in which the mutations in PINK1 gene is responsible for about 2-4\% of EOPD cases in Caucasians (Valente et al., 2004; Bonifati et al., 2005) and 4-9\% in Asian populations (Li et al., 2005; Tan et al., 2006). Similarly, the mutations in PARK7 are also rare in EOPD that represent about $1 \%$ of the total EOPD cases (Abou-Sleiman et al., 2003; Hague et al., 2003), yet the inheritance of these homozygous or heterozygous mutations of PARK7 are almost 100\% (Schulte and Gasser, 2011), therefore making $P A R K 7$ gene as equally important as $P R K N$ gene. On the other hand, GBA and $L R K K 2$ mutations are generally associated with typical PD with the late-onset symptoms, though severe mutations in GBA gene tended to be associated with much early age of the PD onset (Lesage et al., 2011). About $8 \%$ of the LRRK2 mutation carriers were EOPD patients (Healy et al., 2008). Therefore, these genes may offer potential diagnostic values in predicting the EOPD and differentiate them from the typical late-onset $\mathrm{PD}$. Nevertheless, these genetic mutations alone (DNA biomarker) may not be enough to differentiate EOPD from LOPD due to PD heterogeneity and their prevalence in the populations. Thus, a combination of these mutated genes as well other related genes and their respective regulatory microRNAs (stable RNA biomarker) should offer a better diagnostic option as they reflect the actual dysregulation of the cellular states and disease progression of EOPD; hence allowing for a sensitive genetic testing to differentiate EOPD from LOPD.

\section{MICRORNA REGULATORY NETWORK IN PARKINSON DISEASE}

The microRNA regulatory network in PD has been discussed before, particularly in the potential of miRNAs as circulating biomarkers for the diagnosis and treatment of PD (dos Santos et al., 2016; Ma et al., 2016; Marques et al., 2016; Mushtaq et al., 2016; Batistela et al., 2017), in PD progression (HemanAckah et al., 2013) as well as in the oxidative stress pathway (Qiu et al., 2014; Xie and Chen, 2016). However, none of these discussions emphasis on the potential of these miRNAs to differentiate the EOPD from LOPD. From 2011 till now, there were few studies that investigated the miRNAs profile in the EOPD patients and compared them to LOPD patients in which lots of LOPD studies did not include the EOPD comparison (Table 1). Among these identified miRNAs, few of them showed a promise as a potential biomarker for EOPD especially, when their validated targets/genes are involved in PD progression (Figure 1). Among them, miR-34b and miR-34c have been shown to be decreased in the brain tissues in both EOPD and LOPD patients (Miñones-Moyano et al., 2011). Since miR$34 \mathrm{~b}$ and miR-34c are shown to target multiple genes in PD including PRKN and PARK7 (Miñones-Moyano et al., 2011), SNCA (Kabaria et al., 2015b), MAPT (Wu H. et al., 2013), these miRNAs are potentially useful to detect early dysregulation and onset of PD progression. Importantly, miR-331-5p is the only miRNAs that has been identified in plasma of EOPD patients exclusively, with its expression was increased in EOPD patients with no difference was observed in LOPD (Cardo et al., 2013). However, no validated targets/genes were identified for miR331-5p particularly in PD progression, thus these would require further investigation. From these findings, they implied that the role of miRNAs in PD disease progression is significant and thus could also play a role in the determining the age-onset of PD symptoms. Therefore, the potential roles of these miRNAs and their target genes in differentiating EOPD from LOPD will be discussed below, particularly by looking at the various PD pathological events.

\section{MicroRNAs in Mitochondrial Dysregulation}

One of the earliest events in PD pathophysiological processes is the mitochondrial dysregulation (Figure 1). Impairment in oxidative phosphorylation can result in dysregulation of the mitochondrial activity and energy metabolism thus can increase reactive-oxygen-species (ROS) production and oxidative stress, eventually lead to neurotoxicity and death (Dias et al., 2013; $\mathrm{Hu}$ and Wang, 2016). This is evident by the reduced of mitochondrial complex I activity observed in PD patients (Schapira et al., 1989) and peroxisome proliferator-activated receptor gamma coactivator 1 -alpha $(\mathrm{PGC} 1 \alpha)$, which is an 
TABLE 1 | Summary of the altered microRNAs and their targeted genes in Parkinson Disease (PD) with a focus on EOPD and LOPD patients.

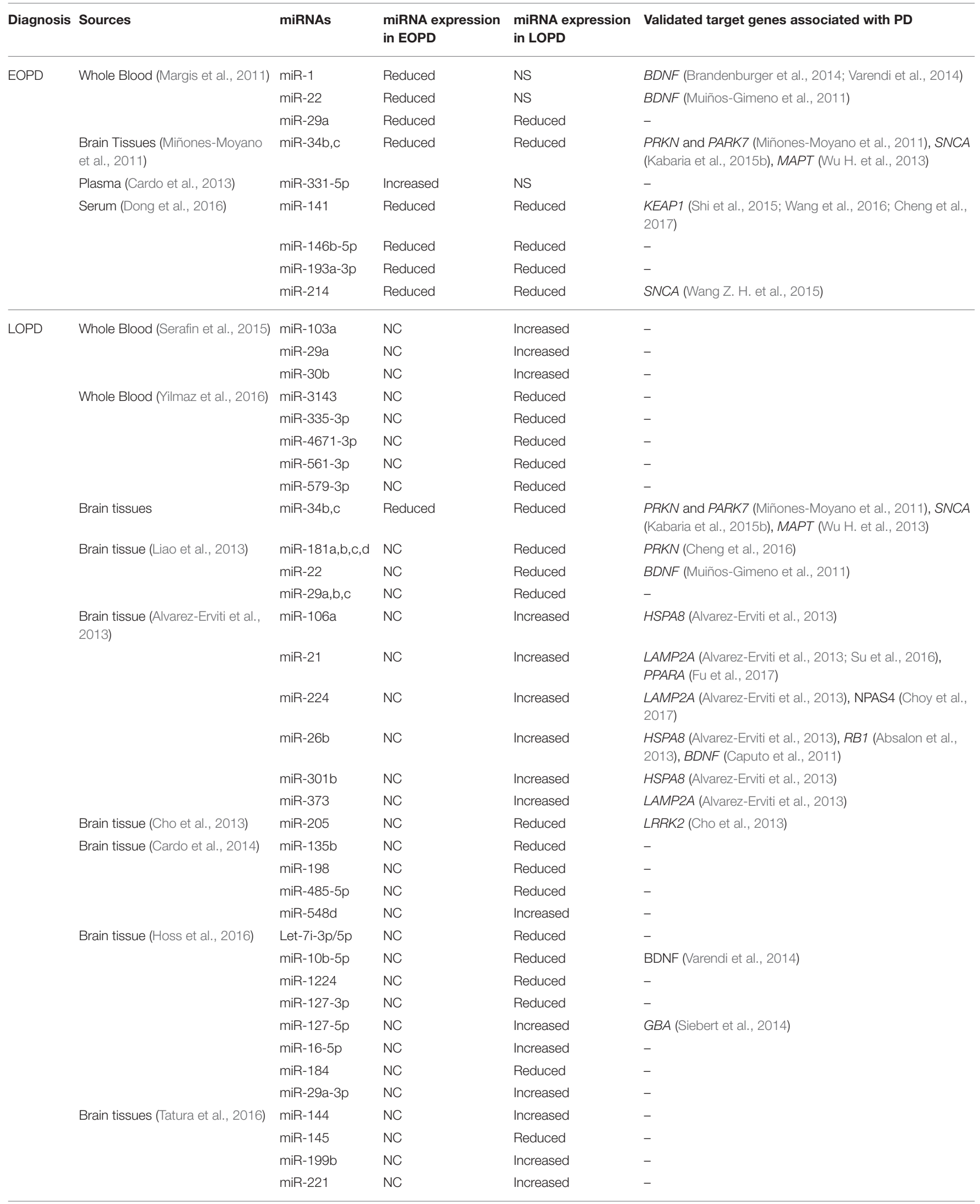


TABLE 1 | Continued

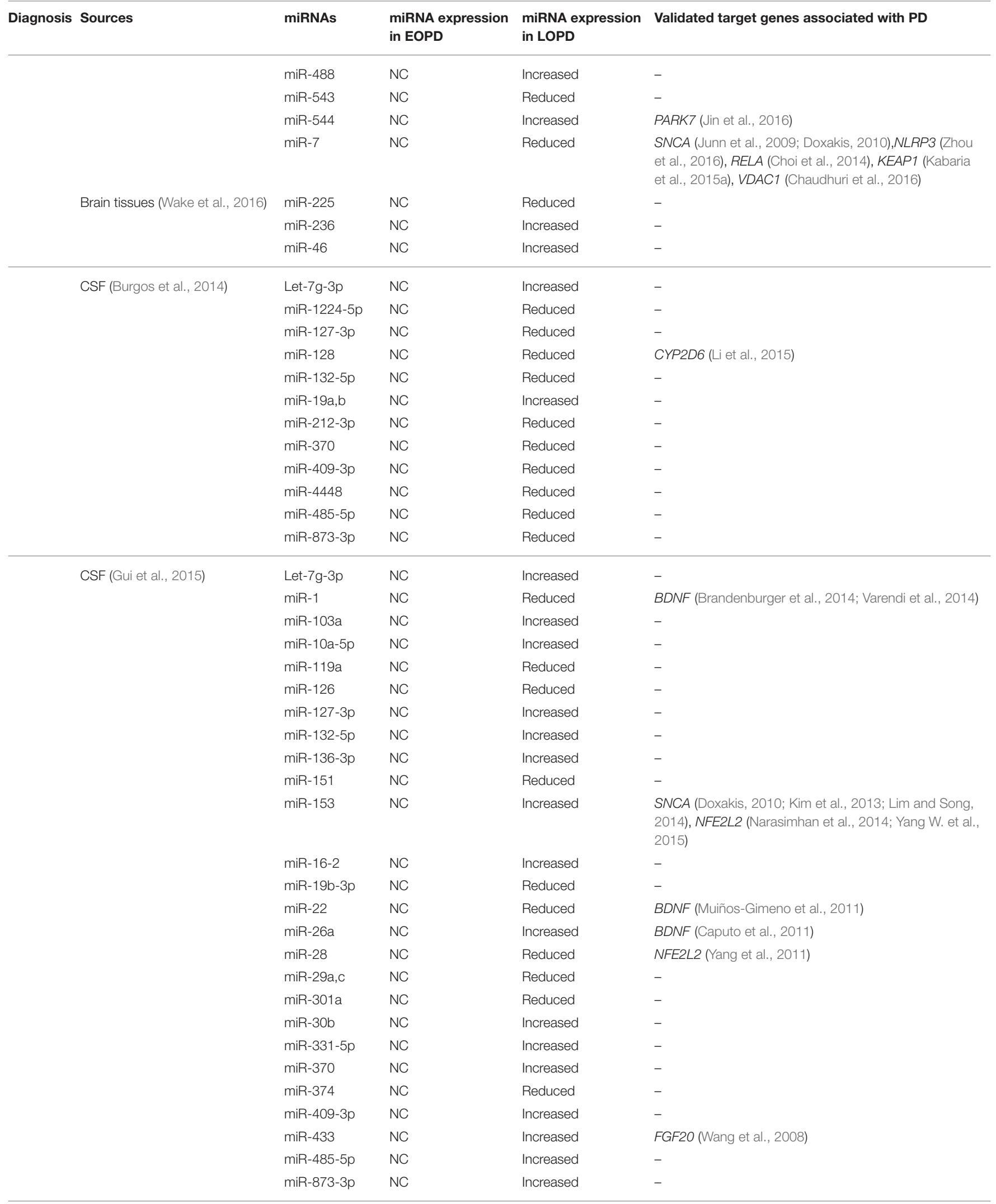


TABLE 1 | Continued

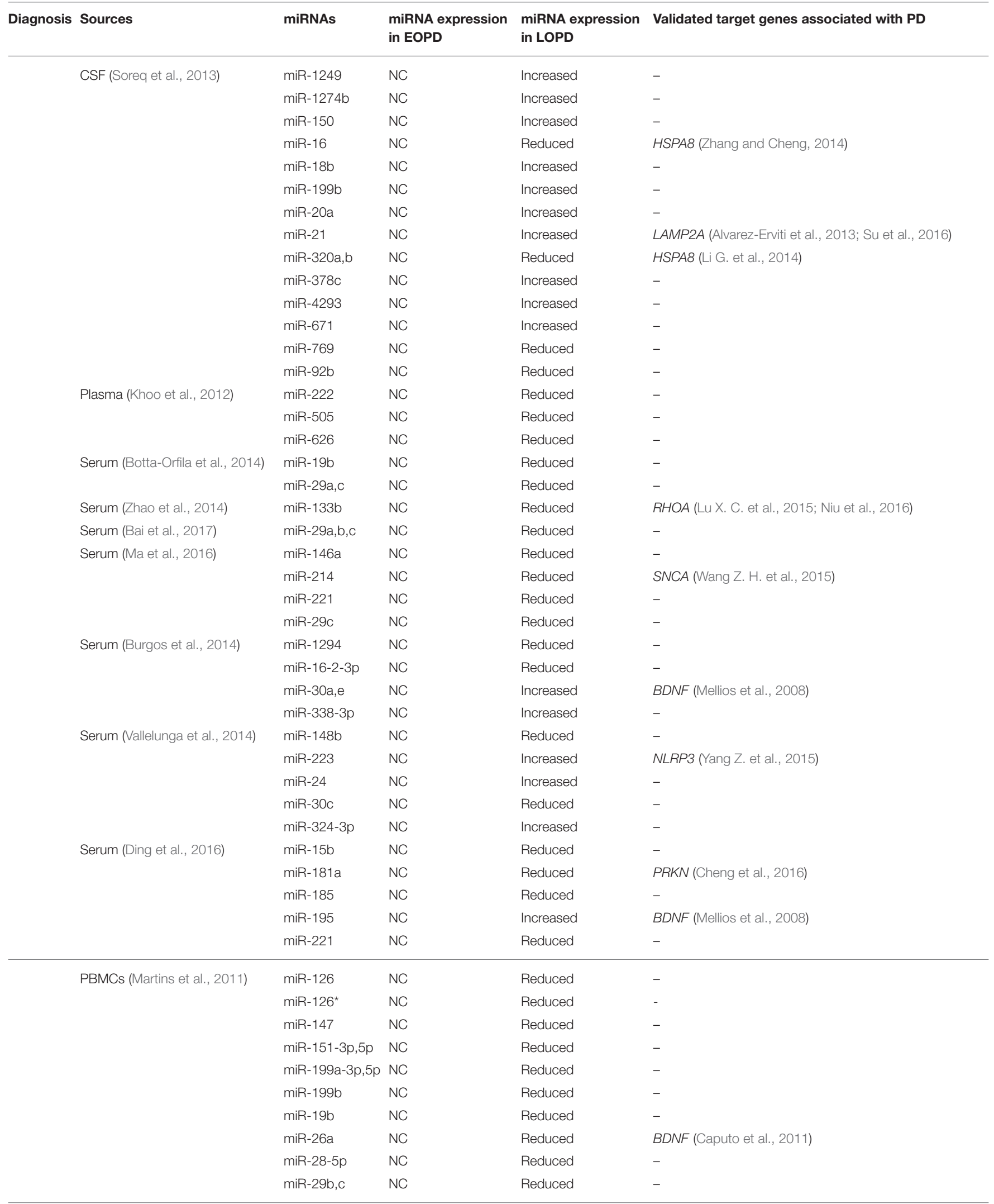


TABLE 1 | Continued

\begin{tabular}{|c|c|c|c|c|}
\hline Diagnosis Sources & miRNAs & $\begin{array}{l}\text { miRNA expression } \\
\text { in EOPD }\end{array}$ & $\begin{array}{l}\text { miRNA expression } \\
\text { in LOPD }\end{array}$ & Validated target genes associated with PD \\
\hline & miR-301a & NC & Reduced & - \\
\hline & miR-335 & NC & Reduced & - \\
\hline & miR-374a,b & NC & Reduced & - \\
\hline
\end{tabular}

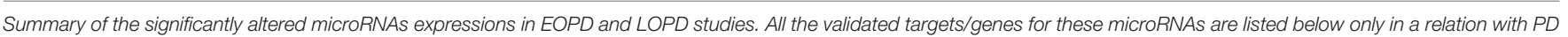

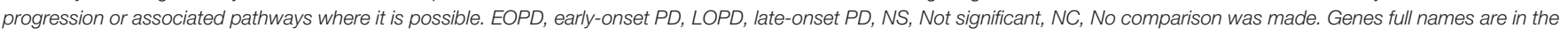
appendix.

important activator for mitochondrial genes, was decreased in PD patients (Zheng et al., 2010). In fact, experimental studies of using neurotoxin, MPTP (Kolata, 1983) and pesticides like rotenone (Perier et al., 2003) showed similar mitochondrial dysregulation thus, re-affirmed that damaged mitochondria as a key mechanism for DA neuronal impairment. Several keys regulators have been identified in mitochondrial dysregulation in PD, particularly the PRKN and PINK1 interaction (Deas et al., 2011). Previous studies have shown that PINK1 is responsible to detect mitochondrial damage and recruits PRKN enzyme to ubiquitinate the damaged mitochondria (Matsuda et al., 2010; Narendra et al., 2010; Vives-Bauza et al., 2010). This ubiquitination tagging will allow the mitophagy to occur and remove the damaged mitochondria (Deas et al., 2011) from the cytoplasm, therefore preventing the parkinsonism to develop. Moreover, PRKN regulates the Zinc finger protein 746 (also known as PARIS) (Shin et al., 2011), which is a transcriptional repressor of PGC1 $\alpha$ gene (Scarpulla, 2008). Dyregulation of PGC1 $\alpha$ expression will affects energy metabolism and mitochondrial biogenesis (Wu et al., 1999). In the progression of PD due to nitrosative stress and ROS, suppression of PRKN gene expression resulted in an accumulation of ZNF746 in the cytosol (LaVoie et al., 2005). The formation of the ZNF746 complex selectively downregulates nuclear respiratory factor1 that controls transcription of the mitochondrial biogenesis, consequently causes DA degeneration (Shin et al., 2011). Besides PRKN and PINK1, PARK7 or also known as protein deglycase (DJ1) can bind to mitochondrial complex I subunit, NDUFA4 and $\mathrm{NADH}$ dehydrogenase 1 and subsequently prevented PD progression via maintaining the complex 1 activity (Hayashi et al., 2009). Therefore, changes in these genes (PRKN, $P I N K 1$, and PARK7) expression and functions may therefore be indicators of mitochondrial damage and dysregulation that mark the initial progression of PD and neurodegeneration in the patients.

Several studies have implied that miRNAs play crucial role as biomarkers and a therapeutic agent to prevent mitochondrial dysfunction in PD (Figure 1). One such is miR-34b and miR34c that co-regulate both PARK7 and PRKN, as evidently by the suppression of both miRNAs resulted in a significant reduction in the expression of PARK7 and PRKN (Miñones-Moyano et al., 2011). Previous study involving PD patients at different stages of the disease, showed that there was a downregulation of $40-$ $65 \%$ expression of $\mathrm{miR}-34 \mathrm{~b}$ and $\mathrm{miR}-34 \mathrm{c}$ in the brain, both in EOPD and LOPD patients (Miñones-Moyano et al., 2011; Table 1). The findings implied that both of these miRNAs may play a role in pathogenesis of PD rather than a consequence of $\mathrm{PD}$ progression, since those EOPD patients did not received any drug treatment yet (Miñones-Moyano et al., 2011). In addition, suppression of miR-34b/c expressions in the differentiated $\mathrm{SH}$ SY5Y cells also resulted in a moderate reduction of the cell viability, with the presence of altered mitochondrial function, oxidative stress and also the reduction of the total cellular ATP content in the cells (Ma et al., 2013), confirming that the suppression of $\mathrm{miR}-34 \mathrm{~b} / \mathrm{c}$ is an indicator of early progression of PD due to mitochondrial damages in the patients, consistent with the reduced expressions of $\mathrm{miR}-34 \mathrm{~b} / \mathrm{c}$ in both EOPD and LOPD studies (Table 1). Other miRNAs is miR-181a that is highly expressed in the brain (Miska et al., 2004) and can directly regulate PRKN gene expression (Cheng et al., 2016). miR-181a expression found to be reduced in the brain (Liao et al., 2013) and serum (Ding et al., 2016) of LOPD patients. Overexpression of miR-181a suppressed PRKN expression and partially inhibited the removal of dysfunctional mitochondria by mitophagy (Cheng et al., 2016), thus subsequently leads to disruption in energy maintenance and mitochondrial quality control. Importantly, introduction of PRKN back into the cells eliminated those negative effects of miR-181a (Cheng et al., 2016), implying that an increase of miR-181a expression may reflect the onset of mitochondrial dysregulation consistent with the suppression of PRKN. However, in PD patients, none of the EOPD studies showed changes in miR-181a expression whereas in LOPD patients, miR-181a expression was reduced (Table 1). Another miRNAs is miR-544 that was increased in the brain tissues of LOPD patients (Tatura et al., 2016) and can directly bind to 3'UTR of PARK7 mRNA region to suppress PARK7 expression (Jin et al., 2016), however, whether miR-544 is implicated in $\mathrm{PD}$ progression remains unknown. Another miRNA is miR7 that regulates $S N C A$ expression and $\alpha$-synuclein level (Junn et al., 2009; Doxakis, 2013). In experimental model of PD, $\alpha$ synuclein can inhibit mitochondrial complex I activity and causes mitochondrial damage (Martin et al., 2006). This is also showed by an overexpression of pathogenic $\alpha$-synuclein, A53T/A30P that caused mitochondrial fragmentation via dynamin-like 120 $\mathrm{kDa}$ protein, thus implies that $\alpha$-synuclein also play a role in mitochondrial dysregulation. Moreover, miR-7 also regulates mitochondrial permeability via voltage-dependent anion channel 1 (VDAC1) (Chaudhuri et al., 2016), though how this gene 
is involved in $\mathrm{PD}$ progression particularly in mitochondrial dysregulation would require further studies. Intriguingly, a study of the LRRK2 mice model has identified three differentially expressed miRNAs (miR-16, miR-15a, and miR-21) in LRRK2knockout mice compared to wildtype mice (Dorval et al., 2014). These miRNAs were predicted to affect mitochondrial dysfunction and apoptosis following dysregulation of miR16/15 expression (Cimmino et al., 2005; Nishi et al., 2010). Interestingly, in this study (Dorval et al., 2014), miR-103 was found to be down-regulated in transgenic mice expressing PDassociated LRRK2 R1441G mutation when compared to wildtype mice, yet no information of the direct regulation or predicted site of miR-103 in LRRK2 gene was observed. This miR-103 dysregulation may suggest that there are underlying mechanisms of miR-103 regulation of LRRK2 gene which may be implicated in PD progression. Previous study showed that elevated level of LRRK2 protein can induce mitochondrial fragmentation via dynamin-like protein (Wang et al., 2012). Nevertheless, some of these miRNAs were altered in the EOPD patients thus may offer diagnostic potential to differentiate EOPD and LOPD, though more information are needed as the comparison for EOPD patients are lacking in those previous studies (Table 1).

\section{MicroRNAs in $\alpha$-Synuclein Regulation and Protein Control System}

SNCA gene encodes the $\alpha$-synuclein protein and among the important genes that are associated with PD in general, SNCA gene is well-recognized as the main player in $\mathrm{PD}$ pathogenesis, in which mutations or rearrangements of SNCA gene are found in those with autosomal dominant PD (Thomas et al., 2011; Klein and Westenberger, 2012). Genome-wide association studies have demonstrated that SNCA gene is significantly associated with PD in multiple populations (Simón-Sánchez et al., 2009; Hamza and Payami, 2010; Tan et al., 2014; Guo et al., 2015; Foo et al., 2017). There is evidence of the SNCA gene susceptibility alleles affecting the expression and plasma level of SNCA (Bekris et al., 2010; Mata et al., 2010), thus reaffirming the important role of SNCA in PD susceptibility. Structurally, $\alpha$-synuclein is a protein with a natively unfolded monomer which forms $\beta$-sheetrich soluble oligomers (Outeiro et al., 2009; Stefanis, 2012). Mutated $\alpha$-synuclein protein has a tendency to aggregate and forms a mature fibril which in turn increases the inclination to form LB (Dawson et al., 2010; Stefanis, 2012). Moreover, the accumulation of transmissible $\alpha$-synuclein aggregates in a cell can be transferable to another cell thus causing a cumulative risk of the LB spreading across the neurons, and eventually inducing major cells deaths (Dauer and Przedborski, 2003; Recasens et al., 2014). Intriguingly, higher levels of normal nonmutated $\alpha$-synuclein protein also increases $\alpha$-synuclein protein aggregation and LB formation in PD patients (Singleton et al., 2003), suggesting that slight changes in SNCA gene expression or $\alpha$-synuclein protein level will trigger PD progression regardless of the mutational status of SNCA gene or $\alpha$-synuclein protein. Therefore, it is important that SNCA gene expression is tightly regulated in the brain and hence, miRNA regulatory network of SNCA gene expression may play important roles in triggering the
$\mathrm{PD}$ progression and can be the potential biomarkers to identify EOPD.

Several microRNAs are shown to be able to regulate SNCA gene expression (Figure 1; Recasens et al., 2016), and few of them are significantly been altered in EOPD patients (Table 1, Figure 1). Previous study of miRNA expression profiling in brain tissues of $\mathrm{PD}$ patients revealed that decreased expression of miR-34b and miR-34c in amygdala region of the brain can be detected in EOPD patients even without any pre-motor symptoms, though similar $\mathrm{miR}-34 \mathrm{~b} / \mathrm{c}$ reduction was also seen in LOPD patients (Miñones-Moyano et al., 2011). miR-34b/c have been shown to regulate SNCA gene expression and $\alpha-$ synuclein protein as well as neuronal toxicity, due to miR$34 \mathrm{~b}$, and miR-34c can directly bind to $3^{\prime} \mathrm{UTR}$ of SNCA mRNA (Kabaria et al., 2015b). Inhibition of miR-34b and miR-34c expression in SH-SY5Y neuronal cells caused an increase of $\alpha$ synuclein protein levels and promoted $\alpha$-synuclein aggregation (Kabaria et al., 2015b). Importantly, in this study (Kabaria et al., 2015b), a single-nucleotide polymorphism (SNP) in SNCA gene, rs10024743 which causes a change of $U$ to $G$ nucleotide at the $3^{\prime}$ UTR of SNCA mRNA, inhibited the miR-34b binding to SNCA mRNA. These findings suggest that the role of genetic susceptibility in SNCA gene can alter the outcome of miRNA regulation and subsequently contribute to $\mathrm{PD}$. Besides that, a previous study that used four miRNAs as serum biomarkers to identify EOPD have found that miR-214 was reduced in both EOPD and LOPD patients, when compared to normal controls, yet its expression did not differ between EOPD and LOPD groups (Table 1; Dong et al., 2016). Like miR-34b/c, miR-214 has also can regulate SNCA gene expression and $\alpha$-synuclein protein (Wang Z. H. et al., 2015). In fact, miR-214 regulatory action of SNCA mRNA expression is linked with the mechanisms of neuroprotection in Resveratrol, a potential therapeutic drug treatment in PD (Albani et al., 2010), therefore implying that this miRNA may have been the molecular regulator of interest in the mechanism of the resveratrol-therapy in PD. Another is miR-7 that is highly expressed in the neurons and can also bind directly to the $3^{\prime}$ UTR of SNCA mRNA (Junn et al., 2009; Doxakis, 2013). miR-7 controls the expression of SNCA gene by decreasing the mRNA stability rather than modifying the protein translation rate (Ma et al., 2013). Suppression of SNCA gene expression by miR-7 will inhibit proteasome impairment and protect the cells from oxidative stress (Junn et al., 2009). In fact, this neuroprotective of miR-7 against $\alpha$-synuclein aggregates has been replicated in various experimental conditions to induce cell death, including due to impaired mitochondrial activity (Choi et al., 2014; Fragkouli and Doxakis, 2014) or genetic mutation of A53T in SNCA gene (Fan et al., 2016; Zhou et al., 2016). Despite these neuroprotective actions of miR-7, only one LOPD study actually showed the differentially expressed miR-7 in human samples (Table 1), in which its expression was reduced in LOPD patients at the region of gyri cinguli (Tatura et al., 2016). This is particularly important as these findings may imply that miR-7 regulation of $\alpha$-synuclein is more complicated than the normal direct-mRNA binding and suppression, seen in in vitro cells or experimental animals or it may suggest that miR-7 regulates multiple target genes thus its expression is highly maintained or 


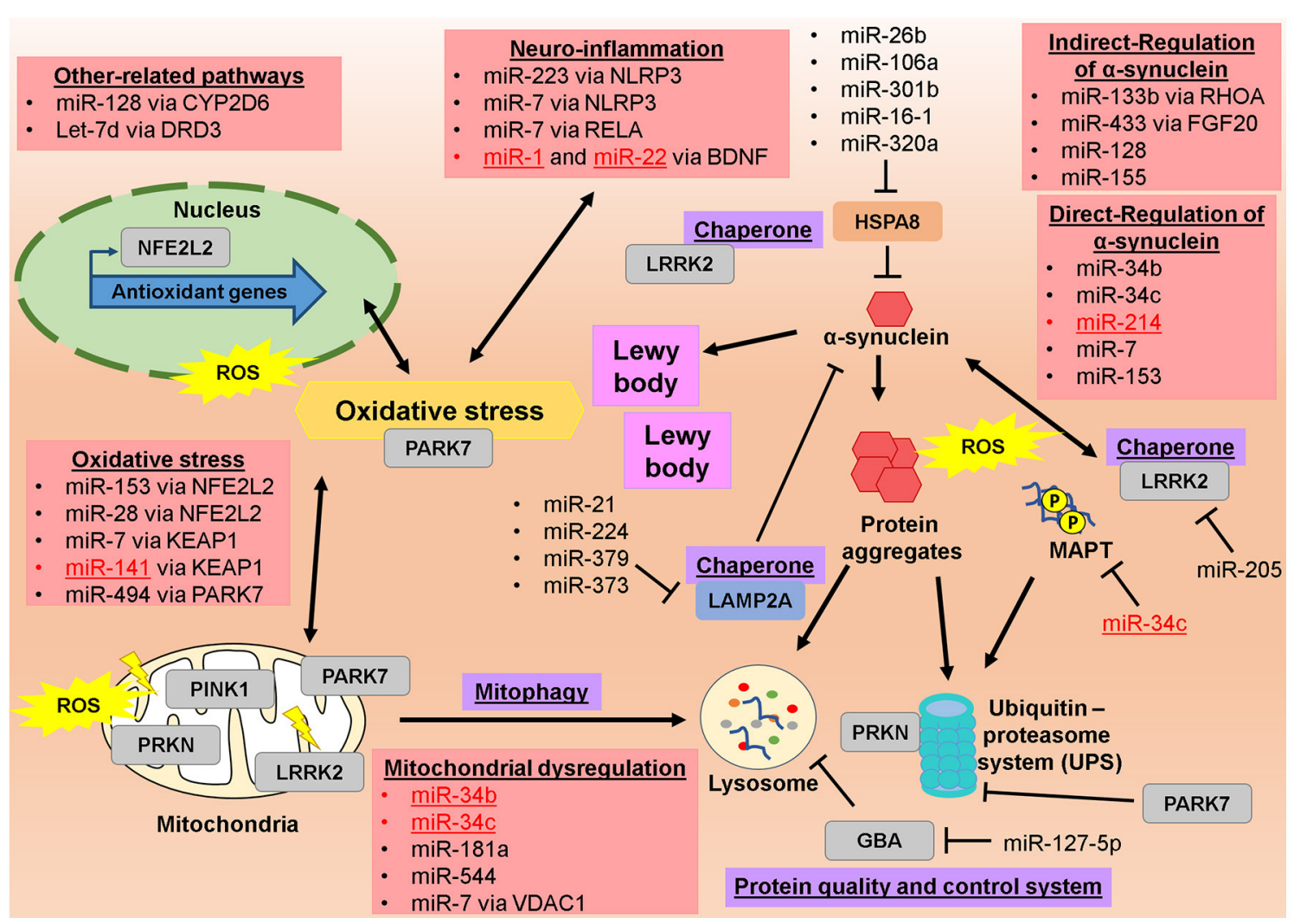

FIGURE 1 | Illustrated regulatory network of altered microRNAs and their targeted genes in pathophysiology of Parkinson's disease. Altered microRNAs from EOPD and LOPD studies are significantly involved in the regulating various molecules in pathophysiological of PD, particularly in mitochondrial dysfunction, oxidative stress, neuro-inflammation, and toxic protein accumulation. Red-colored microRNAs are significantly altered in EOPD patients. Genes full names are in the appendix.

there are other underlying regulators. This is partially supported by a previous study that showed SNCA gene expression can be synergistically suppressed by combination of miR-7 and miR-153 action (Doxakis, 2010; Kim et al., 2013; Fragkouli and Doxakis, 2014; Lim and Song, 2014), in which endogenous $\alpha$-synuclein protein level was 30-40\% reduced (Doxakis, 2010). Like miR-7, miR-153 is also highly expressed in the brain and can directly bind to the 3'UTR of SNCA mRNA (Doxakis, 2010; Kim et al., 2013; Lim and Song, 2014). This combined regulatory action of miR-7 and miR-153 may therefore explain the lack of alteration in miR-7 and miR-153 expression in PD patients. However, none of these microRNAs are specific enough to differentiate the EOPD from LOPD patients as both miR-34b and c were also altered in LOPD patients (Table 1). The fact that no association of SNCA gene was observed in the susceptibility of EOPD (Martin et al., 2011; Schulte and Gasser, 2011) and this fate is also shared by their regulatory miRNAs, these may imply that measuring SNCA gene expression may not suitable for early diagnosis of PD. Nevertheless, some these miRNAs were significantly altered in EOPD patients even with no symptoms observed therefore they offer some potential as biomarkers to differentiate EOPD. Further information is needed to explore and identify more regulatory biomarkers in EOPD, as the current studies were limited in numbers (Table 1).
The role of $\alpha$-synuclein in the brain is currently unclear thus investigating on other miRNAs that indirectly regulate $S N C A$ gene expression and $\alpha$-synuclein protein may provide additional information. Intriguingly, lysosomal-associated membrane protein 2A (LAMP2A) and heat shock protein family A member 8 (HSPA8) can also regulate $\alpha$-synuclein protein level via chaperone-mediated autophagy (Vogiatzi et al., 2008; Alvarez-Erviti et al., 2010). Thus, few miRNAs like miR-21, miR-224, miR-379, and miR-373 that regulate LAMP2A expression (Alvarez-Erviti et al., 2013; Su et al., 2016) and miR26b, miR-106a, miR-301b, miR-16-1, and miR-320a that regulate HSPA8 expression (Alvarez-Erviti et al., 2013; Li G. et al., 2014; Zhang and Cheng, 2014) could also be considered as potential biomarkers in PD progression, and these were consistent with their altered expressions in LOPD studies (Table 1). Similar indirect regulation of SNCA gene expression by other miRNAs has also been observed, including miR-133b via RAS homolog family member A (RHOA) (Lu X. C. et al., 2015; Niu et al., 2016), miR-433 via fibroblast growth factor 20 (FGF20) (Wang et al., 2008), miR-128 (Decressac et al., 2013), and miR-155 (Thome et al., 2016), which resulted in changes of SNCA expression and protein level. Given that some of these microRNAs were found to be significantly altered in LOPD studies (Table 1), thus this neuroprotection of miRNAs network in regulating $\alpha$-synuclein 
protein level may therefore potentially be used as biomarker for PD progression, though their roles in differentiating EOPD would requires more investigations, as there was no comparison of EOPD in those previous LOPD studies (Table 1).

Besides $\alpha$-synuclein, other proteins in the brain have been identified to cause PD, with evidence of dysregulation of protein quality and control system. One such is the LRRK2 gene that is a candidate gene in autosomal dominant PD (Lesage and Brice, 2009; Kett and Dauer, 2012). LRRK2 is primarily involved in the regulation of neurite maintenance and neuronal survival (MacLeod et al., 2006). Previous study was done in rats to investigate the relationship between $L R R K 2$ and $\alpha$-synuclein found that the increase of striatal $\alpha$-synuclein protein level also increased the mRNA level of LRRK2 (Gehrke et al., 2010). In fact, regardless of the mutational status of LRRK2 gene in PD patients with or without LB pathology, $\sim 20-100 \%$ of $\alpha$-synuclein-positive LB also contained high levels of LRRK2 mRNA (Daher et al., 2014), which suggests that LRRK2 and $\alpha$ synuclein have synergetic effects (Guerreiro et al., 2013). Besides that, a soluble microtubule-associated protein tau (MAPT) that modulates the stability of axonal microtubules (Greggio et al., 2006) had been shown to play a role in the PD progression by interacting with LRRK2. Analogous to the amyloid formation by $\alpha$-synuclein, MAPT can also form aggregates which deposit into neurofibrillary tangles (Li J.-Q. et al., 2014). There was a significant elevation of phosphorylated MAPT at Thr181 and Ser396 locations in LRRK2-overexpressing cells (Kawakami et al., 2014). This increase in MAPT phosphorylation was reduced by LRRK2 knockdown only at position Thr181, suggesting that LRRK2 positively regulates MAPT phosphorylation at the Thr181 location only. While at the Ser396 location, the MAPT phosphorylation was induced by LRRK2 protein due to unknown mechanism (Li J.-Q. et al., 2014). Nevertheless, these phosphorylated MAPT proteins are implicated in PD progression, especially in the role of toxic protein accumulation. Consequently, overexpression of LRRK2 expression led to reduced locomotor activity and loss of DA (Saha et al., 2009; Serafin et al., 2014), suggesting that LRRK2 plays an important role in conferring early susceptibility to $\mathrm{PD}$, particularly in controlling the protein levels. Like LRRK2, GBA protein which is a lysosomal membrane protein that cleaves the glycosylceramide (Winfield et al., 1997) also plays a role in protein control system. The loss of lysosomal function arising from dysregulation of GBA will lead to cell toxicity due to accumulation of toxic proteins that can contribute to PD progression (Goker-Alpan et al., 2004). A pilot study on the Jewish population, found that N370S, $\mathrm{L} 444 \mathrm{P}, \mathrm{T} 369 \mathrm{M}$, and $\mathrm{R} 469 \mathrm{H}$ mutations in the GBA gene were associated with PD (Clark et al., 2005), though these findings have not been replicated in other populations. Further studies are needed to confirm the role of GBA in progression of $\mathrm{PD}$, particularly in EOPD, as this gene is currently been associated with LOPD susceptibility (Martin et al., 2011; Schulte and Gasser, 2011). Similar to GBA, ubiquitin-proteasome system (UPS) that comprises of three enzymes, E1, E2 and E3 also been implicated in PD (McNaught et al., 2002). This is supported by the role of PRKN, which has E3 ligase function and loss of PRKN activity caused DA neuron loss without formation of LB (Cook et al.,
2012). However, unlike GBA, several mutations in $P R K N$ gene have been associated with EOPD (Deng et al., 2008; Chen H. et al., 2016), which exclusively indicates that PRKN plays important roles in early events of $\mathrm{PD}$, particularly in EOPD progression.

Several miRNAs have been shown to regulate $L R R K 2$ and $G B A$ expression (Table 1, Figure 1). A previous study of PD patients compared to healthy controls showed that the circulating levels of miR-335-3p, miR-561-3p, and miR-579-3p were associated with PD susceptibility, with miR-561-3p having the strongest association (Saha et al., 2009). In fact, in comparison between LOPD patients and normal controls also revealed that miR-335$3 p$, miR-561-3p, and miR-579-3p were reduced in whole blood (Yilmaz et al., 2016) and PBMCs (Martins et al., 2011) samples. However, these miRNAs were only predicted to target LRRK2 gene (Saha et al., 2009), with no evidence of direct regulation. The only confirmed regulatory miRNAs for LRRK2 is miR-205 that can directly bind to $3^{\prime} \mathrm{UTR}$ region of $L R R K 2 \mathrm{mRNA}$ and this miRNA was down-regulated in LOPD patients (Cho et al., 2013). Interestingly, miR-205 prevented neurite outgrowth defects in neurons expressing PD-related LRRK2 R1441G mutants (Cho et al., 2013), thus suggesting that this miRNA can protect the progression of PD due to LRRK2 genetic susceptibility, which may be a potential therapeutic approach in $L R R K 2 \mathrm{PD}$ patients. Another study that compared LRRK2-mutated PD patients to healthy controls (Botta-Orfila et al., 2014), has identified three differentially expressed miRNAs (miR-29c, miR-29a, and miR19a) in LRRK2-mutated PD patients. Among these miRNAs, two of them (miR-29c and miR-29a) were also found to be differentially expressed in idiopathic PD. As both LRRK2 PD and idiopathic PD shared similar molecular pathways dysregulation (Botta-Orfila et al., 2014), it implied that the LRRK2 gene may play a role in early onset of the disease. As for the MAPT gene, miR-34c have been shown to directly regulate MAPT phosphorylation and expression yet this was only shown in gastric cancer (Wu H. et al., 2013). Indirect regulation of MAPT phosphorylation was also identified, in which miR-26b regulates RBI (Absalon et al., 2013) and miR-138 regulates RARA/GSK-3 $\beta$ pathway (Wang X. et al., 2015), that resulted in suppression of MAPT phosphorylation. As for GBA gene, miR-16-5p, and miR$195-5 \mathrm{p}$ are predicted to regulate $G B A$ expression, yet only miR127-5p was shown to reduce GBA activity and protein synthesis (Siebert et al., 2014), and may contribute to neuronal cell toxicity and PD progression. This is in agreement with previous findings as miR-127-5p expression was increased in the brain tissue of LOPD patients (Hoss et al., 2016), consistent with the findings that GBA gene is altered in LOPD patients and certain mutations in $G B A$ were tended to be associated with EOPD (Martin et al., 2011; Schulte and Gasser, 2011). However, to what extend that $L R R K 2$ and GBA genes and their regulatory miRNAs can be used to differentiate and identify EOPD in the patients is still unclear, but they surely are reasonable biomarkers for LOPD patients.

\section{MicroRNAs in Oxidative Stress}

Another implicated pathway in PD is the oxidative stress that plays important role in disease progression including (1) increasing DNA and mitochondrial DNA mutation, (2) dysregulation of protein homeostasis/degradation, (3) 
regulation of dopamine release, and (4) disruption of cellular self-defense, protection and survival (Dias et al., 2013). Experimental study of PD showed that increased ROS production and alteration of antioxidants were observed (Cassarino et al., 1997). In fact, endogenous antioxidant, the nuclear factor erythroid 2-related factor 2 (NFE2L2) significantly translocate from the cytoplasm into the nucleus to activate antioxidant activity genes in PD (Ramsey et al., 2007). Usually, NFE2L2 is primarily been suppressed by Kelch-like ECHassociated protein 1 (KEAP1, a NFE2L2 sequester protein) in cytoplasm, but upon under oxidative stress, NFE2L2 activates the expression NADPH quinine oxidoreductase 1, heme oxygenase-1, superoxide dismutase, glutathione and many other antioxidant agents/proteins (Satoh et al., 2006; Zhang et al., 2013). Independent of KEAP1 regulation, NFE2L2 expression can also be regulated by protein kinase $\mathrm{C}$ and glycogen synthase kinase 3 beta or epigenetic factors (Bryan et al., 2013). Importantly, NFE2L2 gene and its genetic variants have been implicated as a possible marker for EOPD in Australian PD study (Todorovic et al., 2015), thus confirming the role of oxidative stress in EOPD progression. Another important molecule in oxidative stress is PARK7 that can stabilize NFE2L2 and able to regulate superoxide dismutase 1 via interaction with ERK1/2-ELK1 pathway (Wang et al., 2011). Previous studies also showed that PARK7 also acts as an antioxidant (Taira et al., 2004) and as a redox-sensor protein to prevent $\alpha$-synuclein protein aggregation (Abou-Sleiman et al., 2003; Shendelman et al., 2004). PARK7 is proposed to be involved in mitochondrial protection by directly inhibits $20 \mathrm{~S}$ proteasome activity and recruits NADPH quinone oxidoreductase- 1 to co-regulate $20 \mathrm{~S}$ proteasome activity via stabilization of NFE2L2 (Moscovitz et al., 2015). Similarly to NFE2L2, hemochromatosis gene is also been considered as a potential biomarker for EOPD (Bartzokis et al., 2004), due to its role in iron metabolism and iron-redox balance in oxidative stress (Faucheux et al., 2003). However, recent studies did not find strong relationship of this gene variants, C282Y and H63D with PD in various populations (Aamodt et al., 2007; Duan et al., 2015; Xia et al., 2015), therefore may imply that the role of this hemochromatosis gene in $\mathrm{PD}$ may require further investigation.

Several microRNAs that were identified as biomarkers in PD patients are also implicated in oxidative stress via the genes above (Figure 1). One such is miR-153 that can directly regulates NFE2L2 expression and overexpression of miR-153 led to increase of ROS production in the cells (Narasimhan et al., 2014; Yang W. et al., 2015). This is particularly relevant, as miR153 expression was increased in CSF of LOPD patients (Gui et al., 2015), which indicates that there are dysregulation of oxidative stress and antioxidant system, consistent with miR153 regulatory role on NFE2L2. Besides miR-153, miR-7 can also regulate NFE2L2 pathway via direct binding to $3^{\prime} \mathrm{UTR}$ of KEAP1 mRNA (Kabaria et al., 2015a). Similarly, miR-141 also regulates KEAP1 expression (Shi et al., 2015; Wang et al., 2016; Cheng et al., 2017), whereas miR-28 directly regulates NFE2L2 mRNA, independently of KEAP1 (Yang et al., 2011), but these relationships were only observed in other cell types. Aside from that, miR-494 was identified before can directly downregulate
PARK7 expression by binding to the $3^{\prime} \mathrm{UTR}$ of PARK7 mRNA and overexpression of miR-494 reduced PARK7 protein levels and resulted in increased susceptibility of the neuron cells to oxidative stress (Xiong et al., 2014). Consequently, ROS production was increased when miR-494 is overexpressed in neuron cells, and this effect was diminished by an introduction of PARK7 into those miR-494 overexpressed cells (Xiong et al., 2014), confirming the negative regulation of PARK7 expression by miR494 that contributes to PD progression. However, expression of miR-494 was not changed in PD patients, regardless of EOPD or LOPD comparison (Table $\mathbf{1}$ ).

\section{MicroRNAs in Neuro-Inflammation}

In relation with oxidative stress, neuro-inflammation and immune response are also implicated as key players in the onset of disease progression for both sporadic and familial PD (Chao et al., 2014; Tiwari and Pal, 2017). In fact, previous studies showed that microglial-mediated inflammatory event happens at the early onset of PD (Ouchi et al., 2005; Iannaccone et al., 2013). In the brain, microglia are the major resident immune cells that provide innate immunity, together with astrocytes and oligodendrocytes (Taylor et al., 2013). Usually, microglia maintains the brain healthy environment with neurotrophic factors like brain-derived neurotrophic factor (BDNF), insulinlike growth factor-1 and interleukin 10 (Taylor et al., 2013). Though, the introduction of toxic pesticides or protein aggregates lead to activation of NFKB pathway (Lee, 2013) and increased neurotoxic factors like inflammatory cytokines ( $\mathrm{TNF} \alpha$, tumor necrosis factor alpha, interleukins like IL-1b), chemokines (MCP1 and CCL2), prostaglandins and pattern recognition receptors like toll-like-receptors and nod-like-receptor (NLRs) (Taylor et al., 2013). Subsequently, uncontrolled inflammation events lead to increase of ROS and oxidative stress and eventually neuronal damage (Taylor et al., 2013). The role of these cytokines and inflammatory factors in PD progression have been discussed recently (Tiwari and Pal, 2017). Among them, NLR family, pyrin domain-containing 1 (NLRP1), 3 (NLRP3) and 5 (NLRP5) are known to contribute to neuroinflammation and neuronal death (Meng et al., 2014; Lawana et al., 2017). Others like alpha-2 macroglobulin (A2M) protein, which is a major component of the brain innate immune system and has been linked with EOPD (Krüger et al., 2000). However, there are studies that shown an opposite relationship and no correlation between A2M and the age-onset of PD (Nicoletti et al., 2002; Tang et al., 2002; Guo et al., 2016). Taken together, these findings suggest that an active inflammatory process in the CNS of PD patients includes innate immune system.

Regulation of inflammatory initiators by microRNAs may provide beneficial outcomes in PD. This is evident by a study of intracerebral hemorrhage in mice revealed that miR-223 can reduce brain edema and inflammation by direct-inhibition of NLRP3 inflammasome (Yang Z. et al., 2015). As miR-223 expression was increased in LOPD patients (Vallelunga et al., 2014), this may indicate that the increase of miR-223 expression in late-stage was probably a negative feedback mechanism to control the neuroinflammation and possibly to reduce cell death in the late-onset of PD. Whereas, miR-7 that also 
regulates NLRP3 (Zhou et al., 2016) and proto-oncogene, NF$\mathrm{kB}$ subunit/p65 protein (RELA) (Choi et al., 2014), its expression was reduced in the brain tissues of LOPD patients (Tatura et al., 2016) thus indicates a loss of miR-7 neuroprotection in PD progression. In a mice MPTP model of $\mathrm{PD}$, an introduction of miR-7116 prevented TNF- $\alpha$ production and loss of DA neurons, due to miR-7116 can directly bind to TNF- $\alpha$ to inhibit its production (He et al., 2017). Even though, miR-7116 was not implicated with EOPD or LOPD studies (Table 1), yet TNF$\alpha$ itself can regulates other miRNAs that are known regulators for mitochondrial function and subsequently can contribute to oxidative stress and apoptosis (Prajapati et al., 2015). Thus, miR7116 may play a greater role in the PD progression, especially in the early stage of inflammatory events. Intriguingly, in EOPD patients, both miR-1, and miR-22 expressions were reduced (Margis et al., 2011), and their common validated target/gene is BDNF (Muiños-Gimeno et al., 2011; Brandenburger et al., 2014; Varendi et al., 2014), which is known to increase dopaminergic neuroprotection (Fumagalli et al., 2006). Therefore, reduced of these microRNAs expression in those EOPD patients may therefore indicates that $B D N F$ expression was up-regulated to promote early rescue of DA neurons, thus these miRNAs may potentially be the biomarkers to differentiate EOPD. Despite that, there are other microRNAs that also regulates BDNF expression, and some of them are been implicated both in EOPD and LOPD patients (Table 1). Whether these miRNAs can be used to differentiate EOPD specifically enough is unknown and requires further investigations on their sensitivity and specificity.

\section{MicroRNAs and Others Genes in Parkinson Disease}

Other pathways than above have also been discussed in the progression of PD (Alonso-Navarro et al., 2014). One such is the drugs and xenobiotics detoxification mechanisms pathways, in which a mice MPTP model of PD study showed that a polymorphism in cytochrome $\mathrm{P} 450$ family two subfamily D member 6 (CYP2D6) caused susceptibility to PD (JiménezJiménez et al., 1991). Following that, others have shown that some of these detoxification genes, GSTM1, GSTT1, and NAT2 have been implicated in PD with controversial associations (Wang and Wang, 2014; Jiménez-Jiménez et al., 2016a). Importantly, CYP2D6 and NAT2 genes have been shown exclusively to be associated with EOPD (Agúndez et al., 1995; Agundez et al., 1998), implying that these detoxification genes would have be suitable as EOPD biomarkers. Similar to that, genes that are involved in dopamine metabolism and transport (DRD3, SLC6A3, MTHFR), also showed to pose a risk for PD (Wu Y.-L. et al., 2013; Zhai et al., 2014; Hassan et al., 2016), with particularly, dopamine receptor D3 (DRD3) gene that has been implicated in EOPD patients (Hassan et al., 2016). Due to heterogeneity of $\mathrm{PD}$, various other genes have also been associated with $\mathrm{PD}$ in one or two populations, including saitohin protein ( $\mathrm{Lu}$ et al., 2014), vitamin D receptor (Gatto et al., 2016), semaphorin 5A (Yu et al., 2014), granulin (Chen Y. et al., 2016), histamine N-methyltransferase (HNMT) (Jiménez-Jiménez et al., 2016b), Ras like without CAAX 2 (Lu Y. et al., 2015; Foo et al.,
2017), syntaxin 1B, parkinson disease 16, FGF20, glycoprotein nmb (International Parkinson's Disease Genomics and Wellcome Trust Case Control, 2011), serine/threonine kinase 39 (Foo et al., 2017) and huntingtin interacting protein 1 related (HIP1R) (Yu et al., 2015) genes. Among these genes, HNMT and HIP1R genes have been found to be implicated with the age-onset of the disease, specifically for HNMT in EOPD (Yang X. et al., 2015) whereas HIP1R gene in LOPD (Yu et al., 2015). The roles of these genes in $\mathrm{PD}$ progression require further investigation, as some of these genes were only reported once in association, while others have controversial relationships with PD.

Among those miRNAs that been investigated in EOPD and LOPD patients, some of them were found to regulate CYP2D6 and DRD3 genes (Table 1, Figure 1). One such is in the comparison between LOPD patients and normal controls, miR-128 expression in CSF samples was found to be reduced (Burgos et al., 2014) and miR-128 can directly bind to CYP2D6 mRNA and suppression its expression (Li et al., 2015), which may indicates that CYP2D6 expression was up-regulated in the LOPD patients, consistent with the needs of CYP2D6 to metabolize the neurotoxins in PD. Although Let-7d was no listed in the differentially expressed microRNAs in EOPD and LOPD studies (Table 1), Let-7d was shown to directly regulate the expression of DRD3 (Zhang et al., 2016), which is also a gene that have been associated with EOPD (Hassan et al., 2016). However, no validated and significant microRNA was found to regulate $H N M T$ and $H I P 1 R$ expression in brain specifically. Despite CYP2D6 gene was associated with EOPD (Agúndez et al., 1995; Agundez et al., 1998) yet, its regulatory miRNA was only found to be significant in LOPD studies. The reason for such discrepancies may due to the fact that those LOPD studies did not include a comparison to EOPD patients thus undermines the searching of those miRNAs as biomarkers in EOPD. Also, the possibility of indirect and underlying regulation of these microRNAs and validated targets/genes may also contribute to the inconsistencies. Nevertheless, these miRNAs and their target genes may offer potential diagnostic values in EOPD, as they are significantly altered in patients and some of their target genes are consistently been involved in PD progression, yet further investigations are required to validate such roles.

\section{CHALLENGES OF USING MIRNA AS BIOMARKERS FOR DIAGNOSIS OF EOPD}

miRNAs have an immense potential as biomarkers for the early diagnosis of PD as they are easily detectable in body fluids and a good number of them correlates with disease progression. Developing a technique to detect PD earlier has become important due to the burden of the disease in which most of the cases are detected when $70-80 \%$ of the dopaminergic neurons are lost (Goldenberg, 1990), thus reducing the efficiency of the treatment and recovery. The idea for an early diagnosis to prevent the neuro-degeneration by a simple blood sampling is enticing, and this would make the diagnosis of PD more efficient and economical (Khoo et al., 2012). Currently, the physicians diagnose PD by carefully taking the patient's neurological history 
and performing a thorough physical examination to detect for the symptoms and signs of PD (Jankovic, 2008). To date, the most accurate testing currently available for $\mathrm{PD}$ is to image the dopamine system and brain metabolism through specialized brain scanning, and these tests could only be performed in specialized imaging centers, therefore can be very expensive (Lees et al., 2009). Thus, using the miRNAs as blood biomarkers or CSF sampling give new strategy to improve the screening and diagnosis of PD. In fact, combination of the genetic mutation (DNA biomarker) together with regulatory miRNAs (stable RNA biomarker) in a screening panel could offer a better diagnostic approach, with an ability to differentiate the onset and progression of PD as well-determine their severity, hence a sensitive molecular testing.

One of the problems in identifying microRNAs as biomarkers for any disease is the inconsistency of expression between circulating microRNA and the tissue expression. There are a few explanations behind this situation. One reason is that changes in the concentrations of ubiquitous miRNAs causing or associated with the pathology of the disease can be limited and do not necessarily reflect their concentrations in the body fluids due to the small amount of miRNAs from the affected organ or tissues spilling into the circulatory system (Sheinerman and Umansky, 2013). Another reason is that the changes in miRNA expression are more prominent at the site of the pathological hallmark for a particular disease (PD: in substantia nigra) (Heman-Ackah et al., 2013). For a disease like PD, due to blood brain barrier, miRNAs from the brain that are detectable in the serum or plasma samples may be very limited (Sheinerman and Umansky, 2013), hence may not reflect the miRNA expression in the tissue. Therefore, identification of these miRNAs for a purpose of marking each step of disease progression would therefore require more extensive and detailed studies.

It is also a huge challenge to pick the ultimate miRNAs as sensitive biomarkers for EOPD patients. Previous studies in EOPD patients (Table 1) revealed that there were about 10 significantly expressed miRNAs in EOPD patients, yet their expression was similarly reduced in both EOPD and LOPD patients, except for miR-1, miR-22, and miR-331-5p. Even with that, miR-1 and miR-22 expressions were also found to be reduced in brain tissue (Liao et al., 2013) and in CSF (Gui et al., 2015) samples of LOPD patients, thus indicates that their expressions are also not specific enough for the detection of EOPD. Therefore, we have only one miRNA, miR-331$5 \mathrm{p}$, in which its expression was increased in EOPD patients (Cardo et al., 2013). Focusing on the brain studies, there is one gene target of miR-331 which is the neuropilin 2 (NRP2) that is shown to promote the cell growth and proliferation of glioblastoma (Epis et al., 2014), yet the role of this gene in PD is unknown. Moreover, miR-331 was implicated in neuroprotection in ischemic cortex (Hunsberger et al., 2012) and therefore may suggest that this miRNA possess significant roles in PD but its function requires further study. The fact that its expression was increased in EOPD (Cardo et al., 2013) and never been implicated in LOPD studies, thus these findings imply that miR-331 has a strong potential as a biomarker for EOPD, though further information and studies are needed to validate its role and relationship in PD. Since the published
EOPD studies was in lacking in numbers when compared to LOPD patients (Table 1), there is a need to explore more miRNA profile in EOPD and compared to LOPD patients. Taken together of these findings in PD, it is clear that early events of $\mathrm{PD}$ progression, particularly in mitochondrial dysfunction, oxidative stress and neuroinflammation may hold the key genes and miRNAs for EOPD diagnosis. Furthermore, from the known mutations in PD, PRKN, PINK1, NFE2L2, A2M, and PARK7 genes (mitochondrial, oxidative genes and neuroinflammation) (Krüger et al., 2000; Klein and Westenberger, 2012; Lin and Farrer, 2014; Todorovic et al., 2015) and other genes like DRD3 (Hassan et al., 2016) and HNMT (Yang $X$. et al., 2015) were showed to be associated with EOPD. Therefore, confirming the roles of these genes in early events of PD progression. So, further investigation are needed to allow for new identification of genes and their regulatory miRNAs thus consequently to find new biomarker for PD. It is also worth to mention that the miRNA-based research in PD is still in early exploring stages and not fully clear yet. Even though there are few discrepancies in the findings and its biological targets, some of these miRNAs showed potentials as biomarkers of EOPD, but the limitations in the amount of the previous published studies as well as the PD heterogeneity may therefore emphasize on the need for further investigations and research.

\section{CONCLUSION}

The characterization and differentiation of EOPD from LOPD may reveal important mechanisms for PD susceptibility and can help tailor the effective management of each subtype. As miRNAs are shown to regulate important genes such as PRKN, PARK7, PINK1, SNCA, and others genes in early event of PD progression, they could potentially be harnessed as biomarkers to diagnose EOPD and possibly to improve the management of PD. Although the idea of miRNA-based biomarkers is tempting, few limitations are needed to be considered. Majority of these miRNAs were found in LOPD studies, and the lack of the comparison to EOPD patients may undermine the actual progression marker by miRNA detection. Second, few of the significantly miRNAs were inconsistently expressed between samples types and studies and some of them were not consistently detected either. Therefore, by selecting the miRNAs in comparison of their targets/genes could provide further clarifications on their roles in diagnosing EOPD. Nevertheless, to what extent these miRNAs can be potentially used as biomarkers for early diagnosis for PD is unknown, and would therefore need extensive studies to characterize their regulatory and functional outcomes in differentiating subsets of PD.

\section{AUTHOR CONTRIBUTIONS}

AA drafted and wrote this manuscript, AS and SS were responsible for manuscript writing, editing and critical evaluation, NA, RJ, and NM were responsible for idea conception, critical evaluation and manuscript review. 


\section{FUNDING}

This review is a part of a research funded by a research grant from Universiti Kebangsaan Malaysia (GUP-2015-040).

\section{ACKNOWLEDGMENTS}

Muhamad Hafiz Bin Hanifa (Faculty of Applied Science, AIMST University), Yong Chee Xhian (Faculty of Biotechnology and

\section{REFERENCES}

Aamodt, A. H., Stovner, L. J., Thorstensen, K., Lydersen, S., White, L. R., and Aasly, J. O. (2007). Prevalence of haemochromatosis gene mutations in Parkinson's disease. J. Neurol. Neurosur. Psychiatry 78, 315-317. doi: 10.1136/jnnp.2006.101352

Abou-Sleiman, P. M., Healy, D. G., Quinn, N., Lees, A. J., and Wood, N. W. (2003). The role of pathogenic DJ-1 mutations in Parkinson's disease. Ann. Neurol. 54, 283-286. doi: 10.1002/ana.10675

Absalon, S., Kochanek, D. M., Raghavan, V., and Krichevsky, A. M. (2013). MiR-26b, Upregulated in Alzheimer's disease, activates cell cycle entry, tauphosphorylation, and apoptosis in postmitotic neurons. J. Neurosci. 33, 14645-14659. doi: 10.1523/JNEUROSCI.1327-13.2013

Agúndez, J. A. G., Jiménez-Jiménez, F. J., Luengo, A., Bernal, M. L., Molina, J. A., Ayuso, L., et al. (1995). Association between the oxidative polymorphism and early onset of Parkinson's disease. Clin. Pharmacol. Ther. 57, 291-298. doi: 10.1016/0009-9236(95)90154-X

Agundez, J. A., Jimenez-Jimenez, F. J., Luengo, A., Molina, J. A., Orti-Pareja, M., Vazquez, A., et al. (1998). Slow allotypic variants of the NAT2 gene and susceptibility to early-onset Parkinson's disease. Neurology 51, 1587-1592. doi: 10.1212/WNL.51.6.1587

Albani, D., Polito, L., Signorini, A., and Forloni, G. (2010). Neuroprotective properties of resveratrol in different neurodegenerative disorders. Biofactors 36, 370-376. doi: 10.1002/biof.118

Alonso-Navarro, H., Jimenez-Jimenez, F. J., Garcia-Martin, E., and Agundez, J. A. (2014). Genomic and pharmacogenomic biomarkers of Parkinson's disease. Curr. Drug Metab. 15, 129-181. doi: 10.2174/138920021502140327175404

Alvarez-Erviti, L., Rodriguez-Oroz, M. C., Cooper, J. M., Caballero, C., Ferrer, I., Obeso, J. A. et al. (2010). Chaperone-mediated autophagy markers in parkinson disease brains. Arch. Neurol. 67, 1464-1472. doi: 10.1001/archneurol.2010.198

Alvarez-Erviti, L., Seow, Y., Schapira, A. H., Rodriguez-Oroz, M. C., Obeso, J. A., and Cooper, J. M. (2013). Influence of microRNA deregulation on chaperonemediated autophagy and $\alpha$-synuclein pathology in Parkinson's disease. Cell Death Dis. 4:e545. doi: 10.1038/cddis.2013.73

Ascherio, A., and Schwarzschild, M. A. (2016). The epidemiology of Parkinson's disease: risk factors and prevention. Lancet Neurol. 15, 1257-1272. doi: 10.1016/S1474-4422(16)30230-7

Ba, F., and Martin, W. R. (2015). Dopamine transporter imaging as a diagnostic tool for parkinsonism and related disorders in clinical practice. Parkinsonism Relat. Disord. 21, 87-94. doi: 10.1016/j.parkreldis.2014.11.007

Bai, X., Tang, Y., Yu, M., Wu, L., Liu, F., Ni, J., et al. (2017). Downregulation of blood serum microRNA 29 family in patients with Parkinson's disease. Sci. Rep. 7:5411. doi: 10.1038/s41598-017-03887-3

Bartel, D. P. (2004). MicroRNAs: genomics, biogenesis, mechanism, and function. Cell 116, 281-297. doi: 10.1016/S0092-8674(04)00045-5

Bartzokis, G., Tishler, T. A., Shin, I.-S., Lu, P. H., and Cummings, J. L. (2004). Brain ferritin iron as a risk factor for age at onset in neurodegenerative diseases. Ann. N. Y. Acad. Sci. 1012, 224-236. doi: 10.1196/annals.1306.019

Batistela, M. S., Josviak, N. D., Sulzbach, C. D., and de Souza, R. L. (2017). An overview of circulating cell-free microRNAs as putative biomarkers in Alzheimer's and Parkinson's Diseases. Int. J. Neurosci. 127, 547-558. doi: 10.1080/00207454.2016.1209754

Bekris, L. M., Mata, I. F., and Zabetian, C. P. (2010). The genetics of Parkinson Disease. J. Geriat. Psychiatry Neurol. 23, 228-242. doi: $10.1177 / 0891988710383572$
Biomolecular Science, Universiti Putra Malaysia) for helping with articles selection.

\section{SUPPLEMENTARY MATERIAL}

The Supplementary Material for this article can be found online at: https://www.frontiersin.org/articles/10.3389/fnmol. 2017.00352/full\#supplementary-material

Bonifati, V., Rohe, C. F., Breedveld, G. J., Fabrizio, E., De Mari, M., Tassorelli, C., et al. (2005). Early-onset parkinsonism associated with PINK1 mutations: frequency, genotypes, and phenotypes. Neurology 65, 87-95. doi: 10.1212/01.wnl.0000167546.39375.82

Botta-Orfila, T., Morat,ó, X., Compta, Y., Lozano, J. J., Falgàs, N., Valldeoriola, F., et al. (2014). Identification of blood serum micro-RNAs associated with idiopathic and LRRK2 Parkinson's disease. J. Neurosci. Res. 92, 1071-1077. doi: 10.1002/jnr.23377

Braak, H., Rüb, U., Gai, W. P., and Del Tredici, K. (2003). Idiopathic Parkinson's disease: possible routes by which vulnerable neuronal types may be subject to neuroinvasion by an unknown pathogen. J. Neural Transm. 110, 517-536. doi: $10.1007 /$ s00702-002-0808-2

Brandenburger, T., Grievink, H., Heinen, N., Barthel, F., Huhn, R., Stachuletz, F., et al. (2014). Effects of remote ischemic preconditioning and myocardial ischemia on microRNA-1 expression in the rat heart in vivo. Shock 42, 234-238. doi: 10.1097/SHK.0000000000000201

Bryan, H. K., Olayanju, A., Goldring, C. E., and Park, B. K. (2013). The Nrf2 cell defence pathway: Keap1-dependent and -independent mechanisms of regulation. Biochem. Pharmacol. 85, 705-717. doi: 10.1016/j.bcp.2012. 11.016

Burgos, K., Malenica, I., Metpally, R., Courtright, A., Rakela, B., Beach, T., et al. (2014). Profiles of extracellular miRNA in cerebrospinal fluid and serum from patients with Alzheimer's and Parkinson's diseases correlate with disease status and features of pathology. PLoS ONE 9:e94839. doi: 10.1371/journal.pone.0094839

Caputo, V., Sinibaldi, L., Fiorentino, A., Parisi, C., Catalanotto, C., Pasini, A., et al. (2011). Brain Derived Neurotrophic Factor (BDNF) expression is regulated by microRNAs miR-26a and miR-26b allele-specific binding. PLoS ONE 6:e28656. doi: 10.1371/journal.pone.0028656

Cardo, L. F., Coto, E., de Mena, L., Ribacoba, R., Moris, G., Menéndez, M., et al. (2013). Profile of microRNAs in the plasma of Parkinson's disease patients and healthy controls. J. Neurol. 260, 1420-1422. doi: 10.1007/s00415-013-6900-8

Cardo, L. F., Coto, E., Ribacoba, R., Menéndez, M., Moris, G., Suárez, E., et al. (2014). MiRNA profile in the substantia nigra of parkinson's disease and healthy subjects. J. Mol. Neurosci. 54, 830-836. doi: 10.1007/s12031-014-0428-y

Cassarino, D. S., Fall, C. P., Swerdlow, R. H., Smith, T. S., Halvorsen, E. M., Miller, S. W., et al. (1997). Elevated reactive oxygen species and antioxidant enzyme activities in animal and cellular models of Parkinson's disease. Biochim. Biophys. Acta 1362, 77-86. doi: 10.1016/S0925-4439(97)00070-7

Chao, Y., Wong, S. C., and Tan, E. K. (2014). Evidence of inflammatory system involvement in Parkinson's Disease. Biomed Res. Int. 2014:308654. doi: 10.1155/2014/308654

Chaudhuri, A. D., Choi, D. C., Kabaria, S., Tran, A., and Junn, E. (2016). MicroRNA-7 regulates the function of mitochondrial permeability transition pore by targeting VDAC1 expression. J. Biol. Chem. 291, 6483-6493. doi: 10.1074/jbc.M115.691352

Chen, H., Huang, X., Yuan, L., Xia, H., Xu, H., Yang, Y., et al. (2016). A homozygous parkin p.G284R mutation in a Chinese family with autosomal recessive juvenile parkinsonism. Neurosci. Lett. 624, 100-104. doi: 10.1016/j.neulet.2016.05.011

Chen, Y., Cao, B., Ou, R., Chen, X., Zhao, B., Wei, Q., et al. (2016). Association analysis of the GRN rs5848 and MAPT rs242557 polymorphisms in Parkinson's disease and multiple system atrophy: a large-scale population-based study and meta-analysis. Int. J. Neurosci. 126, 947-954. doi: $10.3109 / 00207454.2015 .1086345$ 
Cheng, L.-B., Li, K.-R., Yi, N., Li, X.-M., Wang, F., Xue, B., et al. (2017). miRNA141 attenuates UV-induced oxidative stress via activating Keap1-Nrf2 signaling in human retinal pigment epithelium cells and retinal ganglion cells. Oncotarget 8, 13186-13194. doi: 10.18632/oncotarget.14489

Cheng, M., Liu, L., Lao, Y., Liao, W., Liao, M., Luo, X., et al. (2016). MicroRNA181a suppresses parkin-mediated mitophagy and sensitizes neuroblastoma cells to mitochondrial uncoupler-induced apoptosis. Oncotarget 7, 42274-42287. doi: 10.18632/oncotarget.9786

Cho, H. J., Liu, G., Jin, S. M., Parisiadou, L., Xie, C., Yu, J., et al. (2013). MicroRNA205 regulates the expression of Parkinson's disease-related leucine-rich repeat kinase 2 protein. Human Mol. Genet. 22, 608-620. doi: 10.1093/hmg/dds470

Choi, D. C., Chae, Y.-J., Kabaria, S., Chaudhuri, A. D., Jain, M. R., Li, H., et al. (2014). MicroRNA-7 protects against 1-methyl-4-phenylpyridiniuminduced cell death by targeting RelA. J. Neurosci. 34, 12725-12737. doi: 10.1523/JNEUROSCI.0985-14.2014

Choy, F. C., Klarić, T. S., Koblar, S. A., and Lewis, M. D. (2017). miR-744 and miR224 downregulate Npas 4 and affect lineage differentiation potential and neurite development during neural differentiation of mouse embryonic stem cells. Mol. Neurobiol. 54, 3528-3541. doi: 10.1007/s12035-016-9912-4

Cimmino, A., Calin, G. A., Fabbri, M., Iorio, M. V., Ferracin, M., Shimizu, M., et al. (2005). miR-15 and miR-16 induce apoptosis by targeting BCL2. Proc. Natl. Acad. Sci. U.S.A. 102, 13944-13949. doi: 10.1073/pnas.0506654102

Clark, L. N., Nicolai, A., Afridi, S., Harris, J., Mejia-Santana, H., Strug, L., et al. (2005). Pilot association study of the $\beta$-glucocerebrosidase N370S allele and Parkinson's disease in subjects of Jewish ethnicity. Mov. Disord. 20, 100-103. doi: $10.1002 / \mathrm{mds} .20320$

Cook, C., Stetler, C., and Petrucelli, L. (2012). Disruption of protein quality control in Parkinson's Disease. Cold Spring Harb. Perspect. Med. 2:a009423. doi: 10.1101/cshperspect.a009423

Daher, J. P. L., Volpicelli-Daley, L. A., Blackburn, J. P., Moehle, M. S., and West, A. B. (2014). Abrogation of $\alpha$-synuclein-mediated dopaminergic neurodegeneration in LRRK2-deficient rats. Proc. Natl. Acad. Sci. U.S.A.111, 9289-9294. doi: 10.1073/pnas.1403215111

Dauer, W., and Przedborski, S. (2003). Parkinson's Disease. Neuron 39, 889-909. doi: 10.1016/S0896-6273(03)00568-3

Dawson, T. M., Ko, H. S., and Dawson, V. L. (2010). Genetic animal models of Parkinson's disease. Neuron 66, 646-661. doi: 10.1016/j.neuron.2010. 04.034

Deas, E., Wood, N. W., and Plun-Favreau, H. (2011). Mitophagy and Parkinson's disease: The PINK1-parkin link().Biochim. Biophys. Acta 1813, 623-633. doi: 10.1016/j.bbamcr.2010.08.007

Decressac, M., Mattsson, B., Weikop, P., Lundblad, M., Jakobsson, J., and Björklund, A. (2013). TFEB-mediated autophagy rescues midbrain dopamine neurons from $\alpha$-synuclein toxicity. Proc. Natl. Acad. Sci. U.S.A.110, E1817E1826. doi: 10.1073/pnas.1305623110

Deng, H., Le, W., Shahed, J., Xie, W., and Jankovic, J. (2008). Mutation analysis of the parkin and PINK1 genes in American Caucasian early-onset Parkinson disease families. Neurosci. Lett. 430, 18-22. doi: 10.1016/j.neulet.2007. 10.018

Dias, V., Junn, E., and Mouradian, M. M. (2013). The role of oxidative stress in Parkinson's Disease. J. Parkinson's Dis. 3, 461-491. doi: 10.3233/JPD-130230

Ding, H., Huang, Z., Chen, M., Wang, C., Chen, X., Chen, J., et al. (2016). Identification of a panel of five serum miRNAs as a biomarker for Parkinson's disease. Parkinsonism Relat. Disord. 22, 68-73. doi: 10.1016/j.parkreldis.2015.11.014

Dong, H., Wang, C., Lu, S., Yu, C., Huang, L., Feng, W., et al. (2016). A panel of four decreased serum microRNAs as a novel biomarker for early Parkinson's disease. Biomarkers 21, 129-137. doi: 10.3109/1354750X.2015.1118544

Dorval, V., Mandemakers, W., Jolivette, F., Coudert, L., Mazroui, R., De Strooper, B., et al. (2014). Gene and microRNA transcriptome analysis of Parkinson's related LRRK2 mouse models. PLoS ONE 9:e85510. doi: 10.1371/journal.pone.0085510

dos Santos, M. C. T., Bell, R., and da Costa, A. N. (2016). Recent developments in circulating biomarkers in Parkinson's disease: the potential use of miRNAs in a clinical setting. Bioanalysis 8, 2497-2518. doi: 10.4155/bio-2016-0166

Doxakis, E. (2010). Post-transcriptional regulation of $\alpha$-synuclein expression by mir-7 and mir-153. J. Biol. Chem. 285, 12726-12734. doi: $10.1074 /$ jbc.M109.086827
Doxakis, E. (2013). Principles of miRNA-target regulation in Metazoan models. Int. J. Mol. Sci. 14, 16280-16302. doi: 10.3390/ijms140816280

Duan, C., Wang, M., Zhang, Y., Wei, X., Huang, Y., Zhang, H., et al. (2015). $\mathrm{C} 282 \mathrm{Y}$ and $\mathrm{H} 63 \mathrm{D}$ polymorphisms in hemochromatosis gene and risk of Parkinson's Disease. Am. J. Alzheimers Dis. Other Demen. 31, 201-207. doi: $10.1177 / 1533317515602220$

Epis, M. R., Giles, K. M., Candy, P. A., Webster, R. J., and Leedman, P. J. (2014). miR-331-3p regulates expression of neuropilin-2 in glioblastoma. J. Neurooncol.116, 67-75. doi: 10.1007/s11060-013-1271-7

Fan, Z., Lu, M., Qiao, C., Zhou, Y., Ding, J.-H., and Hu, G. (2016). MicroRNA-7 enhances subventricular zone neurogenesis by inhibiting NLRP3/Caspase-1 axis in adult neural stem cells. Mol. Neurobiol. 53, 7057-7069. doi: 10.1007/s12035-015-9620-5

Farrer, M. J. (2006). Genetics of Parkinson disease: paradigm shifts and future prospects. Nat. Rev. Genet. 7, 306-318. doi: 10.1038/nrg1831

Faucheux, B. A., Martin, M.-E., Beaumont, C., Hauw, J.-J., Agid, Y., and Hirsch, E. C. (2003). Neuromelanin associated redox-active iron is increased in the substantia nigra of patients with Parkinson's disease. J. Neurochem. 86, 1142-1148. doi: 10.1046/j.1471-4159.2003.01923.x

Feng, J. Y., Huang, B., Yang, W.-Q., Zhang, Y.-H., Wang, L. M., Wang, L.-J., et al. (2015). The putaminal abnormalities on 3.0T magnetic resonance imaging: can they separate parkinsonism-predominant multiple system atrophy from Parkinson's disease? Acta Radiol. 56, 322-328. doi: 10.1177/0284185114524090

Fereshtehnejad, S.-M., Hadizadeh, H., Farhadi, F., Shahidi, G. A., Delbari, A., and Lökk, J. (2014). Comparison of the psychological symptoms and diseasespecific quality of life between early- and typical-onset Parkinson's Disease patients. Parkinson's Dis. 2014:7. doi: 10.1155/2014/819260

Ferguson, L. W., Rajput, A. H., and Rajput, A. (2015). Early-onset vs. lateonset Parkinson's disease: a clinical-pathological study. Can. J. Neurol. Sci. 43 113-119. doi: $10.1017 /$ cjn.2015.244

Foo, J. N., Tan, L. C., Irwan, I. D., Au, W.-L., Low, H. Q., Prakash, K.-M., et al. (2017). Genome-wide association study of Parkinson's disease in East Asians. Human Mol. Genet. 26, 226-232. doi: 10.1093/hmg/ddw379

Fragkouli, A., and Doxakis, E. (2014). miR-7 and miR-153 protect neurons against $\mathrm{MPP}(+)$-induced cell death via upregulation of mTOR pathway. Front. Cell. Neurosci. 8:182. doi: 10.3389/fncel.2014.00182

Fu, Y., Zhen, J., and Lu, Z. (2017). Synergetic neuroprotective effect of docosahexaenoic acid and aspirin in SH-Y5Y by inhibiting miR21 and activating RXR $\alpha$ and PPAR $\alpha$. DNA Cell Biol. 36, 482-489. doi: 10.1089/dna.2017.3643

Fumagalli, F., Racagni, G., and Riva, M. A. (2006). Shedding light into the role of BDNF in the pharmacotherapy of Parkinson's disease. Pharmacogenomics J. 6, 95-104. doi: 10.1038/sj.tpj.6500360

Gasser, T., Hardy, J., and Mizuno, Y. (2011). Milestones in PD genetics. Mov. Disord. 26, 1042-1048. doi: 10.1002/mds.23637

Gatto, N. M., Paul, K. C., Sinsheimer, J. S., Bronstein, J. M., Bordelon, Y., Rausch, R., et al. (2016). Vitamin D receptor gene polymorphisms and cognitive decline in Parkinson's disease. J. Neurol. Sci. 370, 100-106. doi: 10.1016/j.jns.2016.09.013

Gehrke, S., Imai, Y., Sokol, N., and Lu, B. (2010). Pathogenic LRRK2 negatively regulates microRNA-mediated translational repression. Nature 466, 637-641. doi: 10.1038/nature09191

Goker-Alpan, O., Schiffmann, R., LaMarca, M. E., Nussbaum, R. L., McInerneyLeo, A., and Sidransky, E. (2004). Parkinsonism among Gaucher disease carriers. J. Med. Genet. 41, 937-940. doi: 10.1136/jmg.2004.024455

Goldenberg, G. (1990). Performance of concurrent non-motor tasks in parkinson's disease. J. Neurol. 237, 191-196. doi: 10.1007/BF00314593

Greggio, E., Jain, S., Kingsbury, A., Bandopadhyay, R., Lewis, P., Kaganovich, A., et al. (2006). Kinase activity is required for the toxic effects of mutant LRRK2/dardarin. Neurobiol. Dis. 23, 329-341. doi: 10.1016/j.nbd.2006. 04.001

Guerreiro, P. S., Huang, Y., Gysbers, A., Cheng, D., Gai, W. P., Outeiro, T. F., et al. (2013). LRRK2 interactions with $\alpha$-synuclein in Parkinson's disease brains and in cell models. J. Mol. Med. (Berl). 91, 513-522. doi: 10.1007/s00109-0120984-y

Gui, Y., Liu, H., Zhang, L., Lv, W., and Hu, X. (2015). Altered microRNA profiles in cerebrospinal fluid exosome in Parkinson disease and Alzheimer disease. Oncotarget 6, 37043-37053. doi: 10.18632/oncotarget.6158 
Guo, J.-F., Li, K., Yu, R.-L., Sun, Q.-Y., Wang, L., Yao, L.-Y., et al. (2015). Polygenic determinants of Parkinson's disease in a Chinese population. Neurobiol. Aging 36, 1765.e1761-1765.e1766. doi: 10.1016/j.neurobiolaging.2014.12.030

Guo, X., Tang, P., Li, X., Chong, L., Zhang, X., and Li, R. (2016). Association between two $\alpha$-2-macroglobulin gene polymorphisms and Parkinson's disease: a meta-analysis. Int. J. Neurosci. 126, 193-198. doi: 10.3109/00207454.2014.996641

Gwinn, K., David, K. K., Swanson-Fischer, C., Albin, R., Hillaire-Clarke, C. S., Sieber, B.-A., et al. (2017). Parkinson's disease biomarkers: perspective from the NINDS Parkinson's Disease biomarkers program. Biomark. Med. 11, 451-473. doi: 10.2217/bmm-2016-0370

Hague, S., Rogaeva, E., Hernandez, D., Gulick, C., Singleton, A., Hanson, M., et al. (2003). Early-onset Parkinson's disease caused by a compound heterozygous DJ-1 mutation. Ann. Neurol. 54, 271-274. doi: 10.1002/ana.10663

Hamza, T. H., and Payami, H. (2010). The heritability of risk and age at onset of Parkinson's disease after accounting for known genetic risk factors. J. Human Genet. 55, 241-243. doi: 10.1038/jhg.2010.13

Hardy, J., Lewis, P., Revesz, T., Lees, A., and Paisan-Ruiz, C. (2009). The genetics of Parkinson's syndromes: a critical review. Curr. Opin. Genet. Dev. 19, 254-265. doi: 10.1016/j.gde.2009.03.008

Hassan, A., Heckman, M. G., Ahlskog, J. E., Wszolek, Z. K., Serie, D. J., Uitti, R. J., et al. (2016). Association of Parkinson disease age of onset with DRD2, DRD3 and GRIN2B polymorphisms. Parkinsonism Relat. Disord. 22, 102-105. doi: 10.1016/j.parkreldis.2015.11.016

Hayashi, T., Ishimori, C., Takahashi-Niki, K., Taira, T., Kim, Y. C., Maita, H., et al. (2009). DJ-1 binds to mitochondrial complex I and maintains its activity. Biochem. Biophys. Res. Commun. 390, 667-672. doi: 10.1016/j.bbrc.2009. 10.025

He, Q., Wang, Q., Yuan, C., and Wang, Y. (2017). Downregulation of miR-7116$5 \mathrm{p}$ in microglia by MPP + sensitizes TNF- $\alpha$ production to induce dopaminergic neuron damage. Glia 65, 1251-1263. doi: 10.1002/glia.23153

Healy, D. G., Falchi, M., O’Sullivan, S. S., Bonifati, V., Durr, A., Bressman, S., et al. (2008). Phenotype, genotype, and worldwide genetic penetrance of LRRK2associated Parkinson's disease: a case-control study. Lancet Neurol. 7, 583-590. doi: 10.1016/S1474-4422(08)70117-0

Heman-Ackah, S. M., Hallegger, M., Rao, M. S., and Wood, M. J. (2013). RISC in PD: the impact of microRNAs in Parkinson's disease cellular and molecular pathogenesis. Front. Mol. Neurosci. 6:40. doi: 10.3389/fnmol.2013.00040

Hoss, A. G., Labadorf, A., Beach, T. G., Latourelle, J. C., and Myers, R. H. (2016). microRNA profiles in Parkinson's disease prefrontal cortex. Front. Aging Neurosci. 8:36. doi: 10.3389/fnagi.2016.00036

Hu, Q., and Wang, G. (2016). Mitochondrial dysfunction in Parkinson's disease. Transl. Neurodegeneration 5:14. doi: 10.1186/s40035-016-0060-6

Hunsberger, J. G., Fessler, E. B., Wang, Z., Elkahloun, A. G., and Chuang, D.M. (2012). Post-insult valproic acid-regulated microRNAs: potential targets for cerebral ischemia. Am. J. Transl. Res. 4, 316-332.

Hwang, I., Sohn, C.-H., Kang, K. M., Jeon, B. S., Kim, H.-J., Choi, S. H., et al. (2015). Differentiation of parkinsonism-predominant multiple system atrophy from idiopathic Parkinson disease using 3T susceptibility-weighted MR imaging, focusing on putaminal change and lesion asymmetry. Am. J. Neuroradiol. 36, 2227-2234. doi: 10.3174/ajnr.A4442

Iannaccone, S., Cerami, C., Alessio, M., Garibotto, V., Panzacchi, A., Olivieri, S., et al. (2013). In vivo microglia activation in very early dementia with Lewy bodies, comparison with Parkinson's disease. Parkinsonism Relat. Disord. 19, 47-52. doi: 10.1016/j.parkreldis.2012.07.002

Inzelberg, R., Schecthman, E., Paleacu, D., Zach, L., Bonwitt, R., Carasso, R. L., et al. (2004). Onset and progression of disease in familial and sporadic Parkinson's disease. Am. J. Med. Genet. A 124A, 255-258. doi: 10.1002/ajmg. a. 20405

International Parkinson's Disease Genomics and Wellcome Trust Case Control (2011). A two-stage meta-analysis identifies several new loci for Parkinson's disease. PLoS Genet. 7:e1002142. doi: 10.1371/journal.pgen.1002142

Jankovic, J. (2008). Parkinson's disease: clinical features and diagnosis. J. Neurol. Neurosurg. Psychiatry 79, 368-376. doi: 10.1136/jnnp.2007.131045

Jiménez-Jiménez, F. J., Alonso-Navarro, H., García-Martín, E., and Agúndez, J. A. (2016a). NAT2 polymorphisms and risk for Parkinson's disease: a systematic review and meta-analysis. Expert Opin. Drug Metab. Toxicol. 12, 937-946. doi: 10.1080/17425255.2016.1192127.
Jiménez-Jiménez, F. J., Alonso-Navarro, H., García-Martín, E., and Agúndez, J. A. (2016b). Thr105Ile (rs11558538) polymorphism in the histamine N-methyltransferase (HNMT) gene and risk for Parkinson disease: a PRISMA-compliant systematic review and meta-analysis. Medicine 95:e4147. doi: 10.1097/MD.0000000000004147

Jiménez-Jiménez, F. J., Tabernero, C., Mena, M. A., García de Yébenes, J., Jesús García de Yébenes, M., Casarejos, M. J., et al. (1991). Acute effects of 1-Methyl-4-Phenyl-1, 2, 3, 6-tetrahydropyridine in a model of rat designated a poor metabolizer of debrisoquine. J. Neurochem. 57, 81-87. doi: 10.1111/j.1471-4159.1991.tb02102.x

Jin, S., Dai, Y., Li, C., Fang, X., Han, H., and Wang, D. (2016). MicroRNA-544 inhibits glioma proliferation, invasion and migration but induces cell apoptosis by targeting PARK7. Am. J. Transl. Res. 8, 1826-1837.

Junn, E., Lee, K.-W., Jeong, B. S., Chan, T. W., Im, J.-Y., and Mouradian, M. M. (2009). Repression of $\alpha$-synuclein expression and toxicity by microRNA-7. Proc. Natl. Acad. Sci. U.S.A. 106, 13052-13057. doi: 10.1073/pnas.0906277106

Kabaria, S., Choi, D. C., Chaudhuri, A. D., Jain, M. R., Li, H., and Junn, E. (2015a). MicroRNA-7 activates Nrf2 pathway by targeting Keap1 expression. Free Radic. Biol. Med. 89, 548-556. doi: 10.1016/j.freeradbiomed.2015. 09.010

Kabaria, S., Choi, D. C., Chaudhuri, A. D., Mouradian, M. M., and Junn, E. (2015b). Inhibition of miR-34b and miR-34c enhances $\alpha$-synuclein expression in Parkinson's disease. FEBS Lett. 589, 319-325. doi: 10.1016/j.febslet.2014. 12.014

Kawakami, F., Shimada, N., Ohta, E., Kagiya, G., Kawashima, R., Maekawa, T., et al. (2014). Leucine-rich repeat kinase 2 regulates tau phosphorylation through direct activation of glycogen synthase kinase-3ß. FEBS J. 281, 3-13. doi: 10.1111/febs.12579

Kett, L. R., and Dauer, W. T. (2012). Leucine-rich repeat kinase 2 for beginners: Six key questions. Cold Spring Harb. Perspect. Med. 2:a009407. doi: $10.1101 /$ cshperspect.a009407

Khoo, S. K., Petillo, D., Kang, U. J., Resau, J. H., Berryhill, B., Linder, J., et al. (2012). Plasma-based circulating MicroRNA biomarkers for Parkinson's disease. J. Parkinsons Dis. 2, 321-331. doi: 10.3233/JPD-012144

Kim, H.-J., Park, G., Jeon, B. S., Park, W. Y., and Kim, Y. E. (2013). A mir-153 binding site variation in SNCA in a patient with Parkinson's disease. Mov. Disord. 28, 1755-1756. doi: 10.1002/mds.25505

Klein, C., and Westenberger, A. (2012). Genetics of Parkinson's disease. Cold Spring Harb. Perspect. Med. 2:a008888. doi: 10.1101/cshperspect.a008888

Kolata, G. (1983). Monkey model of Parkinson's disease. Science 220, 705-705.

Kraft, E., Trenkwalder, C., and Auer, D. P. (2002). T2*-weighted MRI differentiates multiple system atrophy from Parkinson's disease. Neurology 59, 1265-1267. doi: 10.1212/01.WNL.0000032757.66992.3C

Krüger, R., Menezes-Saecker, A. M., Schöls, L., Kuhn, W., Müller, T., Woitalla, D., et al. (2000). Genetic analysis of the alpha2-macroglobulin gene in early- and late-onset Parkinson's disease. Neuroreport 11, 2439-2442. doi: 10.1097/00001756-200008030-00020

Langston, J. W., Ballard, P., Tetrud, J. W., and Irwin, I. (1983). Chronic Parkinsonism in humans due to a product of meperidine-analog synthesis. Science 219, 979-980.

LaVoie, M. J., Ostaszewski, B. L., Weihofen, A., Schlossmacher, M. G., and Selkoe, D. J. (2005). Dopamine covalently modifies and functionally inactivates parkin. Nat. Med. 11, 1214-1221. doi: 10.1038/nm1314

Lawana, V., Singh, N., Sarkar, S., Charli, A., Jin, H., Anantharam, V., et al. (2017). Involvement of c-Abl Kinase in microglial activation of NLRP3 inflammasome and impairment in autolysosomal system. J. Neuroimmune Pharmacol. doi: 10.1007/s11481-017-9746-5. [Epub ahead of print].

Lee, M. (2013). Neurotransmitters and microglial-mediated neuroinflammation. Curr. Protein Pept. Sci. 14, 21-32. doi: 10.2174/1389203711314010005

Lees, A. J., Hardy, J., and Revesz, T. (2009). Parkinson's disease. Lancet 373, 2055-2066. doi: 10.1016/S0140-6736(09)60492-X

Lesage, S., and Brice, A. (2009). Parkinson's disease: from monogenic forms to genetic susceptibility factors. Human Mol. Genet. 18, R48-R59. doi: $10.1093 / \mathrm{hmg} / \mathrm{ddp} 012$

Lesage, S., Anheim, M., Condroyer, C., Pollak, P., Durif, F., Dupuits, C., et al. (2011). Large-scale screening of the Gaucher's disease-related glucocerebrosidase gene in Europeans with Parkinson's disease. Human Mol. Genet. 20, 202-210. doi: 10.1093/hmg/ddq454 
Li, G., Yang, H., Zhu, D., Huang, H., Liu, G., and Lun, P. (2014). Targeted suppression of chaperone-mediated autophagy by miR-320a promotes $\alpha$-synuclein aggregation. Int. J. Mol. Sci. 15, 15845-15857. doi: 10.3390/ijms150915845

Li, J., Xie, M., Wang, X., Ouyang, X., Wan, Y., Dong, G., et al. (2015). Sex hormones regulate cerebral drug metabolism via brain miRNAs: Down-regulation of brain CYP2D by androgens reduces the analgesic effects of tramadol. $\mathrm{Br}$. J. Pharmacol. 172, 4639-4654. doi: 10.1111/bph.13206

Li, J.-Q., Tan, L., and Yu, J.-T. (2014). The role of the LRRK2 gene in Parkinsonism. Mol. Neurodegeneration 9:47. doi: 10.1186/1750-1326-9-47

Li, Y., Tomiyama, H., Sato, K., Hatano, Y., Yoshino, H., Atsumi, M., et al. (2005). Clinicogenetic study of PINK1 mutations in autosomal recessive early-onset parkinsonism. Neurology 64, 1955-1957. doi: 10.1212/01.WNL.0000164009.36740.4E

Liao, X.-Y., Wang, W.-W., Yang, Z.-H., Wang, J., Lin, H., Wang, Q.-S., et al. (2013). Microarray analysis of transcriptome of medulla identifies potential biomarkers for Parkinson's disease. Int. J. Genomics 2013, 7. doi: 10.1155/2013/606919

Lim, W., and Song, G. (2014). Identification of novel regulatory genes in development of the Avian reproductive tracts. PLoS ONE 9:e96175. doi: 10.1371/journal.pone.0096175

Lin, M. K., and Farrer, M. J. (2014). Genetics and genomics of Parkinson's disease. Genome Med. 6, 48-48. doi: 10.1186/gm566

Longhena, F., Faustini, G., Missale, C., Pizzi, M., Spano, P., and Bellucci, A. (2017). The contribution of $\alpha$-synuclein spreading to Parkinson's disease synaptopathy. Neural Plast. 2017:5012129. doi: 10.1155/2017/5012129

Lu, S.-S., Gong, F.-F., Feng, F., Hu, C.-Y., Qian, Z.-Z., Wu, Y.-L., et al. (2014). Association of microtubule associated protein tau/Saitohin (MAPT/STH) MAPT_238bp/STH Q7R polymorphisms and Parkinson's disease: a meta-analysis. Biochem. Biophys. Res. Commun. 453, 653-661. doi: 10.1016/j.bbrc.2014.10.013

Lu, X. C., Zheng, J. Y., Tang, L. J., Huang, B. S., Li, K., Tao, Y., et al. (2015). MiR133b promotes neurite outgrowth by targeting RhoA expression. Cell. Physiol. Biochem. 35, 246-258. doi: 10.1159/000369692

Lu, Y., Liu, W., Tan, K., Peng, J., Zhu, Y., and Wang, X. (2015). Genetic association of RIT2 rs12456492 polymorphism and Parkinson's disease susceptibility in Asian populations: a meta-analysis. Sci. Rep. 5:13805. doi: 10.1038/srep13805

Lücking, C. B., Dürr, A., Bonifati, V., Vaughan, J., De Michele, G., Gasser, T., et al. (2000). Association between early-onset Parkinson's disease and mutations in the Parkin gene. N. Engl. J. Med. 342, 1560-1567. doi: 10.1056/NEJM200005253422103

Ma, L., Wei, L., Wu, F., Hu, Z., Liu, Z., and Yuan, W. (2013). Advances with microRNAs in Parkinson's disease research. Drug Des. Dev. Ther. 7, 1103-1113. doi: 10.2147/DDDT.S48500

Ma, W., Li, Y., Wang, C., Xu, F., Wang, M., and Liu, Y. (2016). Serum miR-221 serves as a biomarker for Parkinson's disease. Cell Biochem. Funct. 34, 511-515. doi: $10.1002 / \mathrm{cbf} .3224$

MacLeod, D., Dowman, J., Hammond, R., Leete, T., Inoue, K., and Abeliovich, A. (2006). The familial parkinsonism gene LRRK2 regulates neurite process morphology. Neuron 52, 587-593. doi: 10.1016/j.neuron.2006.10.008

Margis, R., Margis, R., and Rieder, C. R. M. (2011). Identification of blood microRNAs associated to Parkinsons disease. J. Biotechnol. 152, 96-101. doi: 10.1016/j.jbiotec.2011.01.023

Marques, T. M., Kuiperij, H. B., Bruinsma, I. B., van Rumund, A., Aerts, M. B., Esselink, R. A., et al. (2016). MicroRNAs in cerebrospinal fluid as potential biomarkers for Parkinson's disease and multiple system atrophy. Mol. Neurobiol. doi: 10.1007/s12035-016-0253-0. [Epub ahead of print].

Martin, I., Dawson, V. L., and Dawson, T. M. (2011). Recent advances in the genetics of Parkinson's disease. Ann. Rev. Genomics Human Genet. 12, 301-325. doi: 10.1146/annurev-genom-082410-101440

Martin, L. J. (2010). Mitochondrial and cell death mechanisms in neurodegenerative diseases. Pharmaceuticals 3, 839-915. doi: 10.3390/ph3040839

Martin, L. J., Pan, Y., Price, A. C., Sterling, W., Copeland, N. G., Jenkins, N. A., et al. (2006). Parkinson's disease $\alpha$-synuclein transgenic mice develop neuronal mitochondrial degeneration and cell death. J. Neurosci. 26, 41-50. doi: 10.1523/JNEUROSCI.4308-05.2006

Martins, M., Rosa, A., Guedes, L. C., Fonseca, B. V., Gotovac, K., Violante, S., et al. (2011). Convergence of miRNA expression profiling, $\alpha$-synuclein interacton and GWAS in Parkinson's disease. PLoS ONE 6:e25443. doi: 10.1371/journal.pone.0025443

Massano, J., and Bhatia, K. P. (2012). Clinical approach to Parkinson's disease: features, diagnosis, and principles of management. Cold Spring Harb. Perspect. Med. 2:a008870. doi: 10.1101/cshperspect.a008870

Mata, I. F., Shi, M., Agarwal, P., Chung, K. A., Edwards, K. L., Factor, S. A., et al. (2010). A SNCA variant associated with Parkinson's disease and plasma a-Synuclein level. Arch. Neurol. 67, 1350-1356. doi: 10.1001/archneurol. 2010.279

Matsuda, N., Sato, S., Shiba, K., Okatsu, K., Saisho, K., Gautier, C. A., et al. (2010). PINK1 stabilized by mitochondrial depolarization recruits Parkin to damaged mitochondria and activates latent Parkin for mitophagy. J. Cell Biol. 189, 211-221. doi: 10.1083/jcb.200910140

McNaught, K. S. P., Belizaire, R., Jenner, P., Olanow, C. W., and Isacson, O. (2002). Selective loss of $20 \mathrm{~S}$ proteasome $\alpha$-subunits in the substantia nigra pars compacta in Parkinson's disease. Neurosci. Lett. 326, 155-158. doi: 10.1016/S0304-3940(02)00296-3

Mellios, N., Huang, H.-S., Grigorenko, A., Rogaev, E., and Akbarian, S. (2008). A set of differentially expressed miRNAs, including miR-30a-5p, act as posttranscriptional inhibitors of BDNF in prefrontal cortex. Human Mol. Genet. 17, 3030-3042. doi: 10.1093/hmg/ddn201

Meng, X.-F., Wang, X.-L., Tian, X.-J., Yang, Z.-H., Chu, G.-P., Zhang, J., et al. (2014). Nod-Like Receptor Protein 1 Inflammasome Mediates Neuron Injury under High Glucose. Mol. Neurobiol. 49, 673-684. doi: 10.1007/s12035-013-8551-2

Meza-Sosa, K. F., Pedraza-Alva, G., and Pérez-Martínez, L. (2014). MicroRNAs: Key triggers of neuronal cell fate. Front. Cell. Neurosci. 8:175. doi: 10.3389/fncel.2014.00175

Miñones-Moyano, E., Porta, S., Escaramís, G., Rabionet, R., Iraola, S., Kagerbauer, B., et al. (2011). MicroRNA profiling of Parkinson's disease brains identifies early downregulation of $\mathrm{miR}-34 \mathrm{~b} / \mathrm{c}$ which modulate mitochondrial function. Human Mol. Genet. 20, 3067-3078. doi: 10.1093/hmg/ddr210

Miska, E. A., Alvarez-Saavedra, E., Townsend, M., Yoshii, A., Šestan, N., Rakic, P., et al. (2004). Microarray analysis of microRNA expression in the developing mammalian brain. Genome Biol. 5, R68-R68. doi: 10.1186/gb-2004-5-9-r68

Moscovitz, O., Ben-Nissan, G., Fainer, I., Pollack, D., Mizrachi, L., and Sharon, M. (2015). The Parkinson's-associated protein DJ-1 regulates the $20 \mathrm{~S}$ proteasome. Nat. Commun. 6:6609. doi: 10.1038/ncomms7609

Muiños-Gimeno, M., Espinosa-Parrilla, Y., Guidi, M., Kagerbauer, B., Sipil,ä, T., Maron, E., et al. (2011). Human microRNAs miR-22, miR-138-2, miR$148 \mathrm{a}$, and miR-488 are associated with panic disorder and regulate several anxiety candidate genes and related pathways. Biol. Psychiatry 69, 526-533. doi: 10.1016/j.biopsych.2010.10.010

Mushtaq, G., Greig, N. H., Anwar, F., Zamzami, M. A., Choudhry, H., Shaik, M. M. et al. (2016). Mirnas as circulating biomarkers for Alzheimer's disease and Parkinson's disease. Med. Chem. 12, 217-225. doi: $10.2174 / 1573406411666151030112140$

Narasimhan, M., Riar, A. K., Rathinam, M. L., Vedpathak, D., Henderson, G., and Mahimainathan, L. (2014). Hydrogen Peroxide responsive miR153 targets Nrf2/ARE cytoprotection in paraquat induced dopaminergic neurotoxicity(). Toxicol. Lett. 228, 179-191. doi: 10.1016/j.toxlet.2014.05.020

Narendra, D. P., Jin, S. M., Tanaka, A., Suen, D.-F., Gautier, C. A., Shen, J., et al. (2010). PINK1 is selectively stabilized on impaired mitochondria to activate parkin. PLoS Biol. 8:e1000298. doi: 10.1371/journal.pbio.10 00298

Nicoletti, G., Annesi, G., Tomaino, C., Spadafora, P., Pasqua, A. A., Annesi, F., et al. (2002). No evidence of association between the alpha- 2 macroglobulin gene and Parkinson's disease in a case-control sample. Neurosci. Lett. 328, 65-67. doi: 10.1016/S0304-3940(02)00003-4

Nishi, H., Ono, K., Iwanaga, Y., Horie, T., Nagao, K., Takemura, G., et al. (2010). MicroRNA-15b modulates cellular ATP levels and degenerates mitochondria via Arl2 in neonatal rat cardiac myocytes. J. Biol. Chem. 285, 4920-4930. doi: 10.1074/jbc.M109.082610

Niu, M., Xu, R., Wang, J., Hou, B., and Xie, A. (2016). MiR-133b ameliorates axon degeneration induced by MPP+ via targeting RhoA. Neuroscience 325, 39-49. doi: 10.1016/j.neuroscience.2016.03.042

Nuytemans, K., Theuns, J., Cruts, M., and Van Broeckhoven, C. (2010). Genetic etiology of Parkinson disease associated with mutations in the SNCA, PARK2, 
PINK1, PARK7, and LRRK2 genes: a mutation update. Human Mutat. 31, 763-780. doi: 10.1002/humu.21277

Oertel, W., and Schulz, J. B. (2016). Current and experimental treatments of Parkinson disease: a guide for neuroscientists. J. Neurochem. 139, 325-337. doi: $10.1111 /$ jnc. 13750

Oki, M., Hori, S., Asayama, S., Wate, R., Kaneko, S., and Kusaka, H. (2016). Early-onset Parkinson's disease associated with chromosome 22q11.2 deletion syndrome. Intern. Med. 55, 303-305. doi: 10.2169/internalmedicine. 55.5485

Ouchi, Y., Yoshikawa, E., Sekine, Y., Futatsubashi, M., Kanno, T., Ogusu, T., et al. (2005). Microglial activation and dopamine terminal loss in early Parkinson's disease. Ann. Neurol. 57, 168-175. doi: 10.1002/ana.20338

Outeiro, T. F., Klucken, J., Bercury, K., Tetzlaff, J., Putcha, P., Oliveira, L. M., et al. (2009). Dopamine-induced conformational changes in alpha-Synuclein. PLoS ONE 4:e6906. doi: 10.1371/journal.pone.0006906

Perier, C., Bové, J., Vila, M., and Przedborski, S. (2003). The rotenone model of Parkinson's disease. Trends Neurosci. 26, 345-346. doi: 10.1016/S0166-2236(03)00144-9

Periquet, M., Latouche, M., Lohmann, E., Rawal, N., De Michele, G., Ricard, S., et al. (2003). Parkin mutations are frequent in patients with isolated early-onset parkinsonism. Brain 126(Pt 6), 1271-1278. doi: 10.1093/brain/ awg136

Prajapati, P., Sripada, L., Singh, K., Bhatelia, K., Singh, R., and Singh, R. (2015). TNF- $\alpha$ regulates miRNA targeting mitochondrial complex-I and induces cell death in dopaminergic cells. Biochim. Biophys. Acta 1852, 451-461. doi: 10.1016/j.bbadis.2014.11.019

Qiu, L., Tan, E. K., and Zeng, L. (2015). "microRNAs and Neurodegenerative Diseases," in microRNA: Medical Evidence: From Molecular Biology to Clinical Practice, ed G. Santulli (Cham: Springer International Publishing), 85-105.

Qiu, L., Zhang, W., Tan, E. K., and Zeng, L. (2014). Deciphering the function and regulation of microRNAs in Alzheimer's disease and Parkinson's disease. ACS Chem. Neurosci. 5, 884-894. doi: 10.1021/cn500149w

Ramsey, C. P., Glass, C. A., Montgomery, M. B., Lindl, K. A., Ritson, G. P., Chia, L. A., et al. (2007). Expression of Nrf2 in neurodegenerative diseases. J. Neuropathol. Exp. Neurol. 66, 75-85. doi: 10.1097/nen.0b013e31802 d6da9

Recasens, A., Dehay, B., Bov,é, J., Carballo-Carbajal, I., Dovero, S., Pérez-Villalba, A., et al. (2014). Lewy body extracts from Parkinson disease brains trigger $\alpha$-synuclein pathology and neurodegeneration in mice and monkeys. Ann. Neurol. 75, 351-362. doi: 10.1002/ana.24066

Recasens, A., Perier, C., and Sue, C. M. (2016). Role of microRNAs in the regulation of $\alpha$-synuclein expression: A systematic review. Front. Mol. Neurosci. 9:128. doi: 10.3389/fnmol.2016.00128

Saha, S., Guillily, M., Ferree, A., Lanceta, J., Chan, D., Ghosh, J., et al. (2009). LRRK2 modulates vulnerability to mitochondrial dysfunction in C. elegans. J. Neurosci. 29, 9210-9218. doi: 10.1523/JNEUROSCI.2281-09.2009

Satoh, T., Okamoto, S. I., Cui, J., Watanabe, Y., Furuta, K., Suzuki, M., et al. (2006). Activation of the Keap1/Nrf2 pathway for neuroprotection by electrophillic phase II inducers. Proc. Natl. Acad. Sci. U.S.A. 103, 768-773. doi: $10.1073 /$ pnas.0505723102

Scarpulla, R. C. (2008). Nuclear control of respiratory chain expression by nuclear respiratory factors and PGC-1-related coactivator. Ann. N. Y. Acad. Sci. 1147, 321-334. doi: 10.1196/annals.1427.006

Schapira, A. H. V., Cooper, J. M., Dexter, D., Jenner, P., Clark, J. B., and Marsden, C. D. (1989). Mitochondrial complex i deficiency in Parkinson's disease. Lancet 333, 1269. doi: 10.1016/S0140-6736(89)92366-0

Schneider, S. A., and Obeso, J. A. (2015). "Clinical and Pathological Features of Parkinson's Disease," in Behavioral Neurobiology of Huntington's Disease and Parkinson's Disease, eds H. H. P. Nguyen and M. A. Cenci (Berlin, Heidelberg: Springer Berlin Heidelberg), 205-220.

Schrag, A., and Schott, J. M. (2006). Epidemiological, clinical, and genetic characteristics of early-onset parkinsonism. Lancet Neurol. 5, 355-363. doi: 10.1016/S1474-4422(06)70411-2

Schrag, A., Ben-Shlomo, Y., Brown, R., David Marsden, C., and Quinn, N. (1998). Young-onset Parkinson's disease revisited-clinical features, natural history, and mortality. Mov. Disord. 13, 885-894. doi: 10.1002/mds.8701 30605
Schulte, C., and Gasser, T. (2011). Genetic basis of Parkinson's disease: Inheritance, penetrance, and expression. Appl. Clin. Genet. 4, 67-80. doi: 10.2147/TACG.S11639

Sellbach, A. N., Boyle, R. S., Silburn, P. A., and Mellick, G. D. (2006). Parkinson's disease and family history. Parkinsonism Relat. Disord. 12, 399-409. doi: 10.1016/j.parkreldis.2006.03.002

Serafin, A., Foco, L., Blankenburg, H., Picard, A., Zanigni, S., Zanon, A., et al. (2014). Identification of a set of endogenous reference genes for miRNA expression studies in Parkinson's disease blood samples. BMC Res. Notes 7:715. doi: 10.1186/1756-0500-7-715

Serafin, A., Foco, L., Zanigni, S., Blankenburg, H., Picard, A., Zanon, A., et al. (2015). Overexpression of blood microRNAs 103a, 30b, and 29a in L-dopa-treated patients with PD. Neurology 84, 645-653. doi: 10.1212/WNL.0000000000001258

Sheinerman, K. S., and Umansky, S. R. (2013). Circulating cell-free microRNA as biomarkers for screening, diagnosis and monitoring of neurodegenerative diseases and other neurologic pathologies. Front. Cell. Neurosci. 7:150. doi: 10.3389/fncel.2013.00150

Shendelman, S., Jonason, A., Martinat, C., Leete, T., and Abeliovich, A. (2004). DJ-1 Is a Redox-Dependent Molecular Chaperone That Inhibits $\alpha$ Synuclein Aggregate Formation. PLoS Biol. 2:e362. doi: 10.1371/journal.pbio.00 20362

Shi, L., Wu, L., Chen, Z., Yang, J., Chen, X., Yu, F., et al. (2015). MiR-141 Activates Nrf2-dependent antioxidant pathway via down-regulating the expression of Keap1 conferring the resistance of hepatocellular carcinoma cells to 5fluorouracil. Cell. Physiol. Biochem. 35, 2333-2348. doi: 10.1159/000374036

Shin, J.-H., Ko, H. S., Kang, H., Lee, Y., Lee, Y.-I., Pletinkova, O., et al. (2011). PARIS (ZNF746) repression of PGC-1 $\alpha$ contributes to neurodegeneration in Parkinson's disease. Cell 144, 689-702. doi: 10.1016/j.cell.2011.02.010

Siebert, M., Westbroek, W., Chen, Y.-C., Moaven, N., Li, Y., Velayati, A., et al. (2014). Identification of miRNAs that modulate glucocerebrosidase activity in Gaucher disease cells. RNA Biol. 11, 1291-1300. doi: 10.1080/15476286.2014.996085

Simón-Sánchez, J., Schulte, C., Bras, J. M., Sharma, M., Gibbs, J. R., Berg, D., et al. (2009). Genome-wide association study reveals genetic risk underlying Parkinson's disease. Nat. Genet. 41, 1308-1312. doi: 10.1038/ng.487

Singleton, A. B., Farrer, M., Johnson, J., Singleton, A., Hague, S., Kachergus, J., et al. (2003). $\alpha$-Synuclein locus triplication causes Parkinson's disease. Science 302, 841-841. doi: 10.1126/science.1090278

Soreq, L., Salomonis, N., Bronstein, M., Greenberg, D. S., Israel, Z., Bergman, H., et al. (2013). Small RNA sequencing-microarray analyses in Parkinson leukocytes reveal deep brain stimulation-induced splicing changes that classify brain region transcriptomes. Front. Mol. Neurosci. 6:10. doi: $10.3389 /$ fnmol.2013.00010

Spano, M., Signorelli, M., Vitaliani, R., Aguglia, E., and Giometto, B. (2015). The possible involvement of mitochondrial dysfunctions in Lewy body dementia: a systematic review. Funct. Neurol. 30, 151-158. doi: 10.11138/FNeur/2015.30.3.151

Spillantini, M. G., Schmidt, M. L., Lee, V. M. Y., Trojanowski, J. Q., Jakes, R., and Goedert, M. (1997). $\alpha$-Synuclein in Lewy bodies. Nature 388, 839-840.

Stefanis, L. (2012). $\alpha$-Synuclein in Parkinson's disease. Cold Spring Harb. Perspect. Med. 2:a009399. doi: 10.1101/cshperspect.a009399

Su, C., Yang, X., and Lou, J. (2016). Geniposide reduces $\alpha$-synuclein by blocking microRNA-21/lysosome-associated membrane protein 2A interaction in Parkinson disease models. Brain Res. 1644, 98-106. doi: 10.1016/j.brainres.2016.05.011

Taira, T., Saito, Y., Niki, T., Iguchi-Ariga, S. M., Takahashi, K., and Ariga, H. (2004). DJ-1 has a role in antioxidative stress to prevent cell death. EMBO Rep. 5, 213-218. doi: 10.1038/sj.embor.7400074

Tan, E.-K., Yew, K., Chua, E., Puvan, K., Shen, H., Lee, E., et al. (2006). PINK1 mutations in sporadic early-onset Parkinson's disease. Mov. Disord. 21, 789-793. doi: 10.1002/mds.20810

Tan, M.-S., Jiang, T., Tan, L., and Yu, J.-T. (2014). Genome-wide association studies in neurology. Ann. Transl. Med. 2:124. doi: 10.3978/j.issn.2305-5839.2014.11.12

Tang, G., Zhang, M., Xie, H., Jiang, S., Wang, Z., Xu, L., et al. (2002). Alpha-2 macroglobulin I1000V polymorphism in Chinese sporadic Alzheimer's disease and Parkinson's disease. Neurosci. Lett. 328, 195-197. doi: 10.1016/S0304-3940(02)00430-5 
Tatura, R., Kraus, T., Giese, A., Arzberger, T., Buchholz, M., Höglinger, G., et al. (2016). Parkinson's disease: SNCA-, PARK2-, and LRRK2- targeting microRNAs elevated in cingulate gyrus. Parkinsonism Relat. Disord. 33, 115-121. doi: 10.1016/j.parkreldis.2016.09.028

Taylor, J. M., Main, B. S., and Crack, P. J. (2013). Neuroinflammation and oxidative stress: Co-conspirators in the pathology of Parkinson's disease. Neurochem. Int. 62, 803-819. doi: 10.1016/j.neuint.2012.12.016

Thomas, B., Mandir, A. S., West, N., Liu, Y., Andrabi, S. A., Stirling, W., et al. (2011). Resistance to MPTP-neurotoxicity in $\alpha$-Synuclein knockout mice is complemented by human $\alpha$-Synuclein and associated with increased $\beta$-Synuclein and Akt activation. PLOS ONE 6:e16706. doi: 10.1371 /journal.pone.0016706

Thome, A. D., Harms, A. S., Volpicelli-Daley, L. A., and Standaert, D. G. (2016). microRNA-155 regulates alpha-synuclein-induced inflammatory responses in models of Parkinson disease. J. Neurosci. 36, 2383-2390. doi: 10.1523/JNEUROSCI.3900-15.2016

Tiwari, P. C., and Pal, R. (2017). The potential role of neuroinflammation and transcription factors in Parkinson disease. Dialogues Clin. Neurosci. 19, 71-80.

Todorovic, M., Newman, J. R., Shan, J., Bentley, S., Wood, S. A., Silburn, P. A., et al. (2015). Comprehensive assessment of genetic sequence variants in the antioxidant 'master regulator' Nrf2 in idiopathic Parkinson's disease. PLoS ONE 10:e128030. doi: 10.1371/journal.pone.0128030

Valente, E. M., Abou-Sleiman, P. M., Caputo, V., Muqit, M. M., Harvey, K., Gispert, S., et al. (2004). Hereditary early-onset parkinson's disease caused by mutations in PINK1. Science 304, 1158-1160. doi: 10.1126/science.1096284

Vallelunga, A., Ragusa, M., Di Mauro, S., Iannitti, T., Pilleri, M., Biundo, R., et al. (2014). Identification of circulating microRNAs for the differential diagnosis of Parkinson's disease and multiple system atrophy. Front. Cell. Neurosci. 8:156. doi: 10.3389/fncel.2014.00156

Varendi, K., Kumar, A., Härma, M.-A., and Andressoo, J.-O. (2014). miR-1, miR10b, miR-155, and miR-191 are novel regulators of BDNF. Cell. Mol. Life Sci. 71, 4443-4456. doi: 10.1007/s00018-014-1628-x

Vives-Bauza, C., Zhou, C., Huang, Y., Cui, M., de Vries, R. L., Kim, J., et al. (2010). PINK1-dependent recruitment of Parkin to mitochondria in mitophagy. Proc. Natl. Acad. Sci. U.S.A. 107, 378-383. doi: 10.1073/pnas.0911187107

Vogiatzi, T., Xilouri, M., Vekrellis, K., and Stefanis, L. (2008). Wild type $\alpha$-synuclein is degraded by chaperone-mediated autophagy and macroautophagy in neuronal cells. J. Biol. Chem. 283, 23542-23556. doi: 10.1074/jbc.M801992200

Wakabayashi, K., Tanji, K., Mori, F., and Takahashi, H. (2007). The Lewy body in Parkinson's disease: molecules implicated in the formation and degradation of $\alpha$-synuclein aggregates. Neuropathology 27, 494-506. doi: 10.1111/j.1440-1789.2007.00803.x

Wake, C., Labadorf, A., Dumitriu, A., Hoss, A. G., Bregu, J., Albrecht, K. H., et al. (2016). Novel microRNA discovery using small RNA sequencing in postmortem human brain. BMC Genomics 17:776. doi: 10.1186/s12864-016-3114-3

Wang, G., van der Walt, J. M., Mayhew, G., Li, Y.-J., Züchner, S., Scott, W. K., et al. (2008). Variation in the miRNA-433 binding site of FGF20 confers risk for Parkinson disease by overexpression of $\alpha$-synuclein. Am. J. Human Genet. 82, 283-289. doi: 10.1016/j.ajhg.2007.09.021

Wang, L.-L., Huang, Y.-H., Yan, C.-Y., Wei, X.-D., Hou, J.-Q., Pu, J.-X., et al. (2016). N-acetylcysteine Ameliorates Prostatitis via miR141 regulating Keap1/Nrf2 signaling. Inflammation 39, 938-947. doi: 10.1007/s10753-016-0327-1

Wang, T., and Wang, B. (2014). Association between Glutathione S-transferase M1/Glutathione S-transferase T1 polymorphisms and Parkinson's disease: a meta-analysis. J. Neurol. Sci. 338, 65-70. doi: 10.1016/j.jns.2013.12.018

Wang, X., Tan, L., Lu, Y., Peng, J., Zhu, Y., Zhang, Y., et al. (2015). MicroRNA-138 promotes tau phosphorylation by targeting retinoic acid receptor alpha. FEBS Lett. 589, 726-729. doi: 10.1016/j.febslet.2015.02.001

Wang, X., Yan, M. H., Fujioka, H., Liu, J., Wilson-Delfosse, A., Chen, S. G., et al. (2012). LRRK2 regulates mitochondrial dynamics and function through direct interaction with DLP1. Human Mol. Genet. 21, 1931-1944. doi: $10.1093 / \mathrm{hmg} / \mathrm{dds} 003$

Wang, Z., Liu, J., Chen, S., Wang, Y., Cao, L., Zhang, Y., et al. (2011). DJ-1 modulates the expression of $\mathrm{Cu} / \mathrm{Zn}$-superoxide dismutase-1 through the Erk1/2-Elk1 pathway in neuroprotection. Ann. Neurol. 70, 591-599. doi: 10.1002/ana.22514
Wang, Z.-H., Zhang, J.-L., Duan, Y.-L., Zhang, Q.-S., Li, G.-F., and Zheng, D.-L. (2015). MicroRNA-214 participates in the neuroprotective effect of Resveratrol via inhibiting $\alpha$-synuclein expression in MPTP-induced Parkinson's disease mouse. Biomed. Pharmacother. 74, 252-256. doi: 10.1016/j.biopha.2015.08.025

Winfield, S. L., Tayebi, N., Martin, B. M., Ginns, E. I., and Sidransky, E. (1997). Identification of three additional genes contiguous to the glucocerebrosidase locus on chromosome 1q21: implications for Gaucher disease. Genome Res. 7, 1020-1026. doi: 10.1101/gr.7.10.1020

Wu, H., Huang, M., Lu, M., Zhu, W., Shu, Y., Cao, P., et al. (2013). Regulation of microtubule-associated protein tau (MAPT) by miR-34c-5p determines the chemosensitivity of gastric cancer to paclitaxel. Cancer Chemother. Pharmacol. 71, 1159-1171. doi: 10.1007/s00280-013-2108-y

Wu, Y.-L., Ding, X.-X., Sun, Y.-H., Yang, H.-Y., and Sun, L. (2013). Methylenetetrahydrofolate reductase (MTHFR) C677T/A1298C polymorphisms and susceptibility to Parkinson's disease: a meta-analysis. J. Neurol. Sci. 335, 14-21. doi: 10.1016/j.jns.2013.09.006

Wu, Z., Puigserver, P., Andersson, U., Zhang, C., Adelmant, G., Mootha, V., et al. (1999). Mechanisms controlling mitochondrial biogenesis and respiration through the thermogenic coactivator PGC-1. Cell 98, 115-124. doi: 10.1016/S0092-8674(00)80611-X

Xia, J., Xu, H., Jiang, H., and Xie, J. (2015). The association between the C282Y and H63D polymorphisms of HFE gene and the risk of Parkinson's disease: a meta-analysis. Neurosci. Lett. 595(Suppl. C), 99-103. doi: 10.1016/j.neulet.2015.04.010

Xie, Y., and Chen, Y. (2016). microRNAs: emerging targets regulating oxidative stress in the models of Parkinson's disease. Front. Neurosci. 10:298. doi: $10.3389 /$ fnins.2016.00298

Xiong, R., Wang, Z., Zhao, Z., Li, H., Chen, W., Zhang, B., et al. (2014). MicroRNA494 reduces DJ-1 expression and exacerbates neurodegeneration. Neurobiol. Aging 35, 705-714. doi: 10.1016/j.neurobiolaging.2013.09.027

Yang, M., Yao, Y., Eades, G., Zhang, Y., and Zhou, Q. (2011). MiR-28 regulates Nrf2 expression through a Keap1-independent mechanism. Breast Cancer Res. Treat. 129, 983-991. doi: 10.1007/s10549-011-1604-1

Yang, W., Shen, Y., Wei, J., and Liu, F. (2015). MicroRNA-153/Nrf-2/GPx1 pathway regulates radiosensitivity and stemness of glioma stem cells via reactive oxygen species. Oncotarget 6, 22006-22027. doi: 10.18632/oncotarget.4292

Yang, X., Liu, C., Zhang, J., Han, H., Wang, X., Liu, Z., et al. (2015). Association of Histamine N-Methyltransferase Thr105Ile Polymorphism with Parkinson's Disease and Schizophrenia in Han Chinese: A Case-Control Study. PLoS ONE 10:e0119692. doi: 10.1371/journal.pone.0119692

Yang, Z., Zhong, L., Xian, R., and Yuan, B. (2015). MicroRNA-223 regulates inflammation and brain injury via feedback to NLRP3 inflammasome after intracerebral hemorrhage. Molecular Immunology 65, 267-276. doi: 10.1016/j.molimm.2014.12.018

Yilmaz, S. G., Geyik, S., Neyal, A. M., Soko, N. D., Bozkurt, H., and Dandara, C. (2016). Hypothesis: do miRNAs targeting the leucine-rich repeat kinase 2 gene (LRRK2) influence parkinson's disease susceptibility? OMICS 20, 224-228. doi: 10.1089/omi.2016.0040

Yu, R.-L., Guo, J.-F., Wang, Y.-Q., Liu, Z.-H., Sun, Z.-F., Su, L., et al (2015). The single nucleotide polymorphism Rs12817488 is associated with Parkinson's disease in the Chinese population. J. Clin. Neurosci. 22, 1002-1004. doi: 10.1016/j.jocn.2014.11.024

Yu, X., Wang, F., and Zhang, J. P. (2014). Meta analysis of the association of rs7702187 SNP in SEMA5A gene with risk of Parkinson's disease. Eur. Rev. Med. Pharmacol. Sci. 18, 900-904.

Zhai, D., Li, S., Zhao, Y., and Lin, Z. (2014). SLC6A3 is a risk factor for Parkinson's disease: a meta-analysis of sixteen years' studies. Neurosci. Lett. 564, 99-104. doi: 10.1016/j.neulet.2013.10.060

Zhang, M., An, C., Gao, Y., Leak, R. K., Chen, J., and Zhang, F. (2013). Emerging roles of Nrf2 and phase II antioxidant enzymes in neuroprotection. Prog. Neurobiol. 100, 30-47. doi: 10.1016/j.pneurobio.2012.09.003

Zhang, Y., Cheng, C., He, D., Shi, W., Fu, C., Wang, X., et al. (2016). Transcriptional gene silencing of dopamine D3 receptor caused by let-7d mimics in immortalized renal proximal tubule cells of rats. Gene 580, 89-95. doi: 10.1016/j.gene.2015.12.071

Zhang, Z., and Cheng, Y. (2014). miR-16-1 promotes the aberrant $\alpha$-synuclein accumulation in Parkinson disease via targeting heat shock protein 70 . Scientific World J. 2014:8. doi: 10.1155/2014/938348 
Zhao, N., Jin, L., Fei, G., Zheng, Z., and Zhong, C. (2014). Serum microRNA-133b is associated with low ceruloplasmin levels in Parkinson's disease. Parkinsonism Relat. Disord. 20, 1177-1180. doi: 10.1016/j.parkreldis.2014.08.016

Zheng, B., Liao, Z., Locascio, J. J., Lesniak, K. A., Roderick, S. S., Watt, M. L., et al. (2010). PGC- $1 \alpha$, A potential therapeutic target for early intervention in parkinson's disease. Sci. Transl. Med. 2, 52ra73-52ra73. doi: 10.1126/scitranslmed.3001059

Zhou, Y., Lu, M., Du, R.-H., Qiao, C., Jiang, C.-Y., Zhang, K.-Z., et al. (2016). MicroRNA-7 targets Nod-like receptor protein 3 inflammasome to modulate neuroinflammation in the pathogenesis of Parkinson's disease. Mol. Neurodegeneration 11, 28. doi: 10.1186/s13024-016-0094-3
Conflict of Interest Statement: The authors declare that the research was conducted in the absence of any commercial or financial relationships that could be construed as a potential conflict of interest.

Copyright (c) 2017 Arshad, Sulaiman, Saperi, Jamal, Mohamed Ibrahim and Abdul Murad. This is an open-access article distributed under the terms of the Creative Commons Attribution License (CC BY). The use, distribution or reproduction in other forums is permitted, provided the original author(s) or licensor are credited and that the original publication in this journal is cited, in accordance with accepted academic practice. No use, distribution or reproduction is permitted which does not comply with these terms. 